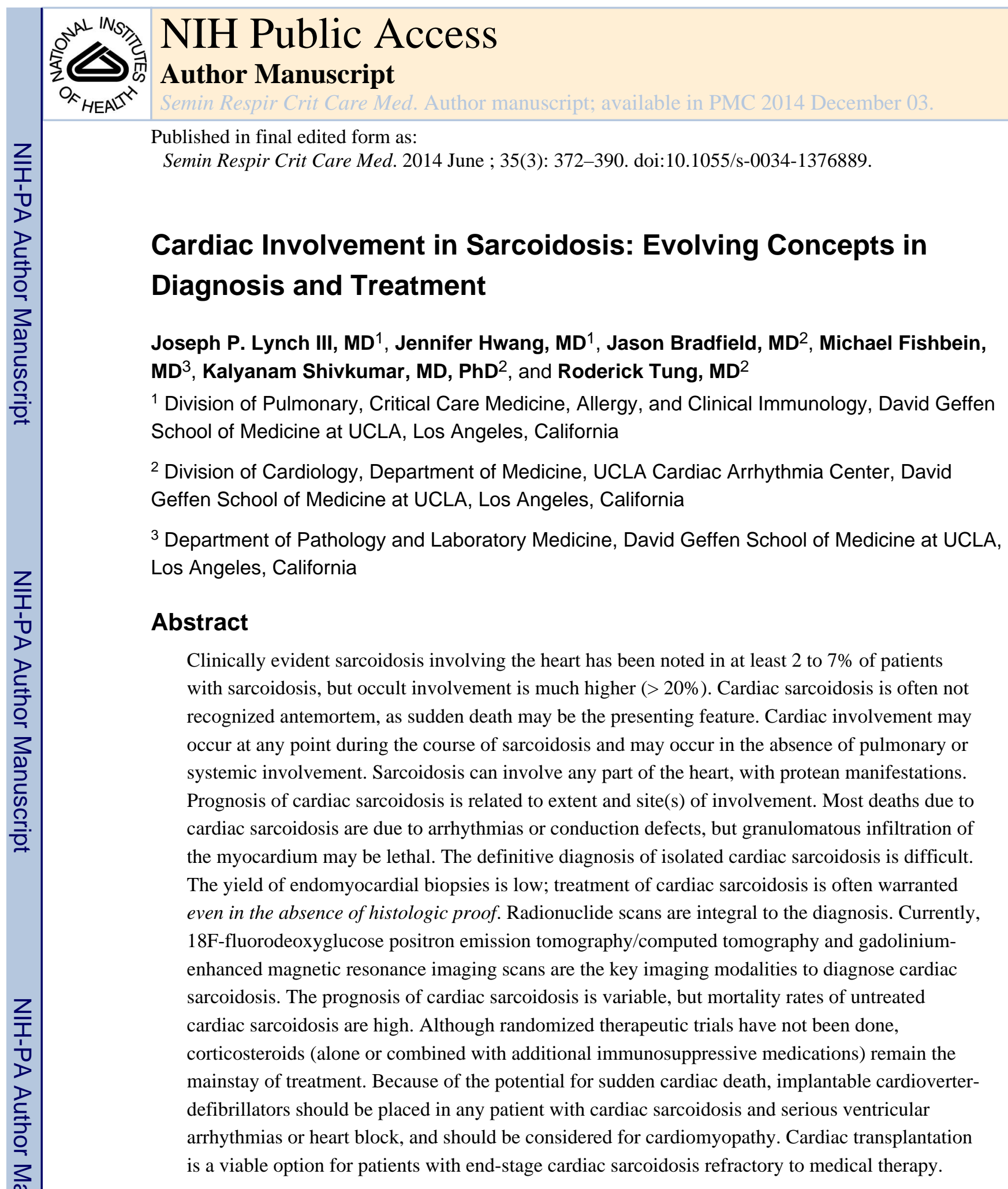

\title{
Keywords
}

sarcoidosis; cardiac; ventricular arrhythmias; cardiomyopathy

Copyright (C) 2014 by Thieme Medical Publishers, Inc.

Address for correspondence Joseph P. Lynch III, MD, Division of Pulmonary, Critical Care Medicine, Allergy, and Clinical Immunology, David Geffen School of Medicine at UCLA, 10833 Le Conte Ave, Room 37-131 CHS, Los Angeles, CA 90095 (jplynch@mednet.ucla.edu). 


\section{Prevalence and Epidemiology}

Clinically evident sarcoidosis involving the heart has been noted in at least 2 to $7 \%$ of patients with sarcoidosis ${ }^{1-8}$ but occult involvement is much higher $(>20 \%) .{ }^{9-13}$ Cardiac sarcoidosis is often not recognized antemortem, as sudden death may be the presenting feature. ${ }^{14-19}$ A recent survey of sarcoid experts underscored lack of agreement in criteria for diagnosis or optimal treatment of cardiac sarcoidosis. ${ }^{20}$ In a 2002 issue of Seminars in Respiratory and Critical Care Medicine, we reviewed cardiac sarcoidosis in depth ${ }^{21}$; in this updated article, we discuss new insights that have developed over the past decade.

\section{Incidence of Cardiac Involvement}

Several necropsy series in the United States and United Kingdom cited pathological evidence for cardiac involvement in 19.5 to $28 \%$ of sarcoid patients. ${ }^{3,14-16,22,23}$ The incidence of cardiac sarcoidosis is higher in Japanese patients with sarcoidosis ${ }^{24-26}$ (50-78\% in necropsy studies). ${ }^{19,27,28}$ In Japan, cardiac involvement is the leading cause of death due to sarcoidosis, accounting for 77 to $85 \%$ of deaths. ${ }^{19,29}$ By contrast, in the United States, 13 to $50 \%$ of sarcoid deaths have been attributed to myocardial involvement. ${ }^{14,30}$

\section{Genetics of Cardiac Sarcoidosis}

The increased frequency of cardiac involvement in Japanese patients with sarcoidosis suggests genetic influences, ${ }^{26,27,31}$ but the specific genes responsible for cardiac sarcoidosis have not been elucidated. ${ }^{32}$ An early study in 26 Japanese patients with cardiac sarcoidosis suggested a higher frequency of the allele tumor necrosis factor-a 2 compared with controls, ${ }^{33}$ but this has not been replicated. In 2008, Myer et al reported a case of a 33-yearold female with cardiomyopathy and nonnecrotizing granulomas on endomyocardial biopsies (EMBs) consistent with cardiac sarcoidosis. ${ }^{34}$ Sequencing of the patient's butyrophilin-like 2 (BTNL2) gene revealed a homozygous $\mathrm{G} \rightarrow \mathrm{A}$ transition in exon 5, constituting variant rs2076530 that was associated with sarcoidosis in some, ${ }^{35,36}$ but not all, ${ }^{37}$ European and North American cohorts. Importantly, a study of 293 Japanese patients with sarcoidosis found no independent genetic association between the rs2076530 BTNL2 polymorphism and susceptibility to sarcoidosis. ${ }^{38}$ However, in a Japanese cohort of 26 patients with cardiac sarcoidosis, polymorphisms along with HLA-DQB1 (in particular DQB1 ${ }^{*} 0601$ ) were significantly associated with disease. ${ }^{39}$ The genetics of sarcoidosis (cardiac and noncardiac) are exceptionally complex, ${ }^{40}$ and are beyond the scope of this article. The genetics of sarcoidosis are elegantly discussed in article "Cardiac Involvement in Sarcoidosis: Evolving Concepts in Diagnosis and Treatment" by Drs. Fischer et al in this issue.

\section{Pathology and Sites of Involvement}

In the 1970s, sentinel publications delineated the salient pathological and clinical features of cardiac sarcoidosis. ${ }^{15,16,19}$ Granulomatous inflammation, the hallmark of sarcoidosis, may involve any part of the heart (i.e., myocardium, endocardium, or pericardium). ${ }^{6,15,16,41}$ Nonnecrotizing granulomas, epithelioid histiocytes, multinucleated giant cells, Schaumann 
bodies or asteroid bodies, patchy fibrosis, and lymphocytic infiltration may be observed $^{6,18,41}$ (Fig. 1A-E).

Sarcoidosis can involve any part of the heart, with protean manifestations. ${ }^{2,15,16,22,42}$ The myocardium is most frequently involved in cardiac sarcoidosis; pericardial and endocardial involvement usually reflect direct extensions of myocardial disease. ${ }^{15,16,24}$ The areas of involvement in descending order of frequency are the left ventricular free wall, interventricular septum (IVS), papillary muscles, right ventricle (RV), and atria. ${ }^{15,43}$ Grossly, the myocardium shows fibrosis in unusual locations. Myocardial scars in unusual locations, not typical for ischemic injury, in the absence of coronary artery disease, in otherwise young individuals, should suggest cardiac sarcoidosis.

\section{Prognosis of Cardiac Sarcoidosis}

Cardiac involvement may occur at any point during the course of sarcoidosis and may occur in the absence of pulmonary or systemic involvement. ${ }^{2,15,16,19,22,44}$ In one necropsy series, 10 of 25 deaths attributed to sarcoid heart disease had no extracardiac disease. ${ }^{43}$ Although the disease is often clinically silent, cardiac sarcoidosis has been associated with an attributable mortality rate of up to 50 to $85 \%$ in autopsy series. ${ }^{19,45}$ In one study of 95 Japanese patients with cardiac sarcoidosis seen between 1984 and 1996, 40 died from cardiac causes during follow-up (congestive heart failure in 29; sudden death in 11). ${ }^{25}$ Overall survival rates were $85 \%$ at 1 year, $60 \%$ at 5 years, and $44 \%$ at 10 years. ${ }^{25}$ In that study, the following parameters were independent predictors of morality by multivariate analysis: (1) New York Heart Association functional class (hazard ratio 7.7 per class I increase, $p=0.0008$ ); (2) left ventricular end-diastolic diameter (hazard ratio $2.6 / 10 \mathrm{~mm}$ increase, $p=0.02$ ); and (3) sustained ventricular tachycardia (VT) (hazard ratio 7.2, $p=$ 0.03). ${ }^{25}$ Fleming and Bailey reported a cohort of 197 patients with cardiac sarcoidosis in the United Kingdom; sudden death occurred in 48 (24\%), and was the presenting symptom in 34 $(17 \%) .{ }^{46}$

Prognosis of cardiac sarcoidosis is related to extent and site (s) of involvement. Most deaths due to cardiac sarcoidosis are due to arrhythmias or conduction defects; progressive heart failure due to massive granulomatous infiltration of the myocardium accounts for at least $25 \%$ of deaths. ${ }^{2,15,16,19,22,24,25}$

In 1977, Roberts et al described 35 necropsy patients with cardiac sarcoidosis at the National Heart, Lung, and Blood Institute (NHLBI) and Armed Forced Institute of Pathology and reviewed 78 previously published necropsies with cardiac sarcoidosis. ${ }^{15}$ Interestingly, 24 of 113 patients $(21 \%)$ had no cardiac signs or symptoms. Among the entire cohort of 113 patients, 108 had sarcoid granulomas in the heart; 5 had myocardial scarring without granulomata. Macroscopic, grossly evident granulomata were present in the heart in 25 of 26 patients with clinically significant cardiac sarcoidosis in the NHLBI subset. Among the 89 patients with clinically evident cardiac dysfunction, two-thirds died suddenly, presumably due to arrhythmias or heart block; $23 \%$ died from progressive heart failure. All patients who died from myocardial sarcoidosis had grossly visible cardiac granulomas at necropsy. All eight patients with left ventricular failure had extensive infiltration of the left ventricle (LV) 
at necropsy. Papillary muscle dysfunction was noted in 16 patients; 8 had ventricular aneurysms. Of the eight patients, seven with ventricular aneurysms had been treated with corticosteroids (CSs), raising the possibility that CS may promote aneurysm formation. Recurrent pericardial effusions were fatal in three patients. In 1978, Silverman et al reviewed 84 consecutive necropsies from patients with sarcoidosis seen at the Johns Hopkins Hospital from 1899 to 1977; 23 patients (27\%) had cardiac (granulomatous) involvement. ${ }^{16}$ Among four patients with widespread grossly evident lesions, three had arrhythmias and sudden unexpected death. Of the 19 patients with microscopic evidence for myocardial granulomas, only 4 had symptoms attributed to cardiac sarcoidosis. In a review of 25 necropsies from patients who died as a result of cardiac sarcoidosis, all had macroscopic lesions involving the myocardium. ${ }^{43}$ Hence, gross evidence of macroscopic lesions are nearly invariably present among patients who die from cardiac sarcoidosis, but small histologic foci of sarcoidosis involving the heart may be clinically silent. ${ }^{15,16,43}$

Nonetheless, aggressive imaging studies to identify active sites of granulomatous inflammation are critical as treatment may avert potentially lethal progression of the cardiac lesion(s).

\section{Conduction Disturbances and Arrhythmias}

Conduction disturbances and arrhythmias are the most common cardiac manifestations and reflect granulomatous infiltration within the conduction system (e.g., sinoatrial node, atrioventricular $[\mathrm{AV}]$ node, or bundle of His) or ventricular walls. ${ }^{2,15,22}$ Although AV block is the most common arrhythmic manifestation of cardiac sarcoid (26-67\%), ${ }^{47}$ bundle branch block (BBB), nonspecific interventricular conduction delay, premature ventricular contractions (PVCs), VT, and other arrhythmias may be observed. ${ }^{2,15,48,49}$ In the series reported by Roberts et al, the following electrocardiogram (ECG) abnormalities were cited: complete heart block (22\%); complete BBB (22\%); VT (17\%); PVCs (29\%); and atrial arrhythmias (16\%). ${ }^{15}$ In an English series of 300 patients with cardiac sarcoidosis, predominant features included: ventricular arrhythmias (VA) (45\%); BBBs (38\%); supraVA (28\%); and sudden death (16\%). ${ }^{2}$ Atrial arrhythmias may reflect atrial dilatation secondary to ventricular dysfunction, pulmonary parenchymal involvement, or direct atrial involvement from granulomas or scar tissue. ${ }^{15,45,47}$ In a retrospective study of 100 patients with cardiac sarcoidosis, $32 \%$ had supra-VA during a mean follow-up period of 5.8 years. ${ }^{50}$ In any sarcoid patient with arrhythmias, early involvement of electrophysiologists as part of a multidisciplinary team is warranted. ${ }^{51}$

\section{Cardiomyopathy}

Extensive myocardial disease may result in dilated cardiomyopathy and heart failure. $5,22,25,52$ In a study of 43 patients with myocardial sarcoidosis seen at the Johns Hopkins Hospital from 1889 to 1991, cardiomyopathy was noted in 21 (49\%) and was associated with a mortality of $62 \% .^{5}$ Other features included: syncope in $14(33 \%)$; heart block in 13 (30\%); and tachyarrhythmias in $12(28 \%)$. In a Japanese study of cardiac sarcoidosis, congestive heart failure was the most common cause of death. ${ }^{52}$ In a subsequent study, these investigators described 95 Japanese patients with cardiac sarcoidosis. ${ }^{25}$ The diagnosis was made at necropsy in 20 patients; in 75 patients, the diagnosis of cardiac 
sarcoidosis was established antemortem. All 75 patients were treated with CSs. During the mean follow-up of 68 months, 29 of 75 patients (39\%) died of congestive heart failure and $11(15 \%)$ died suddenly.

\section{Cardiac Valvular Involvement}

Severe involvement of cardiac valves is uncommon $(<3 \%),{ }^{2,15,16,22,53}$ but valvular dysfunction may result from sarcoid involvement of the papillary muscles. ${ }^{15,45,54}$ The degree of papillary muscle dysfunction is usually mild, but severe granulomatous infiltration mandating mitral valve replacement has been described. ${ }^{53,55}$ Less commonly, the tricuspid, aortic, or pulmonary valves are involved. ${ }^{15}$

\section{Pericardial Involvement}

Infiltration of the pericardium may lead to pericardial effusion ${ }^{15,22,56-62}$ and, rarely, constrictive pericarditis. ${ }^{57}$ In most patients with pericardial involvement, concomitant myocardial involvement is present. ${ }^{15,16,24,62}$ In one study, 13 of 14 sarcoidosis patients with pericardial effusions had abnormal ${ }^{99}$ technetium $\left({ }^{99} \mathrm{Tc}\right)$-pyrophosphate scans, consistent with infiltrative cardiomyopathy. ${ }^{62}$

\section{Cardiac Vasculature}

Coronary arteries are typically normal in patients with cardiac sarcoidosis. Coronary arterial aneurysms, ${ }^{63}$ coronary artery spasm, ${ }^{64}$ acute coronary syndrome, ${ }^{65}$ coronary artery vasculitis, ${ }^{66}$ and ventricular aneuryms ${ }^{2,22,67-71}$ have been described, but are exceptionally rare. Scans in the myocardium in the absence of coronary disease are typical of cardiac sarcoidosis.

\section{Involvement of Other Organs}

Extracardiac involvement is usually present in patients with cardiac sarcoidosis, but symptoms may be absent until the initial presentation with sudden cardiac death. ${ }^{15,43}$ In the necropsy series from the NHLBI, 26 patients died of arrhythmias or conduction disturbances. ${ }^{15}$ In this subset, 25 (96\%) had lymph node involvement; 20 (77\%) had lung involvement; and 17 (68\%) had granulomas on liver biopsy. Among 95 Japanese patients with cardiac sarcoidosis, extracardiac involvement included: pulmonary in 56 patients (59\%); ocular in 39 (41\%); and skin in $16(16 \%) .{ }^{25}$ In a British study of 20 necropsies in patients with cardiac sarcoidosis, other sites of organ involvement included: lung in 19 (95\%); lymph nodes in 19 (95\%); liver in 7 (35\%); and spleen in $7(35 \%){ }^{3}$ In a French study of 41 patients with cardiac sarcoidosis, extracardiac involvement was present in all cases. ${ }^{42}$ In $63 \%$ of cases, cardiac involvement developed during the follow-up of systemic sarcoidosis.

\section{Isolated Cardiac Sarcoidosis}

Isolated cardiac sarcoidosis, once thought to be relatively rare, is much more common than previously suspected. As we previously noted, in a necropsy study, 40\% (12 of 25) patients who died as a result of cardiac sarcoidosis had no signs of extracardiac involvement. ${ }^{43}$ 
Further, in a recent retrospective study, 33 of $52(66 \%)$ patients with cardiac sarcoidosis seen between 2000 and 2010 had disease isolated to the heart.

\section{Diagnosis of Cardiac Sarcoidosis}

The definitive diagnosis of isolated cardiac sarcoidosis is difficult. The yield of EMBs is low and clinicians must often rely on noninvasive imaging to diagnose and follow cardiac sarcoidosis. Treatment of cardiac sarcoidosis is often warranted even in the absence of histologic proof. Guidelines to diagnose cardiac sarcoidosis were developed in 1993 by the Japanese Ministry of Health and Welfare (Table 1) and in 1999 by the research group in the United States conducting the ACCESS (A Case Controlled Etiologic Study of Sarcoidosis) study. ${ }^{74}$ Given the potential mortality associated with cardiac sarcoidosis, early diagnosis and treatment is critical and may be lifesaving. Serum angiotensin converting enzyme levels are insensitive for cardiac sarcoidosis. ${ }^{75}$ ECG abnormalities or cardiac failures are nonspecific and may be related to other causes (e.g., coronary artery disease, idiopathic cardiomyopathy, or severe pulmonary sarcoidosis with cor pulmonale). Techniques to diagnose cardiac sarcoidosis have evolved over the past two decades. Currently, gadoliniumenhanced cardiac magnetic resonance imaging (MRI) ${ }^{76-78}$ and positron emission tomography/computed tomography (PET/CT) ${ }^{76,79-81}$ are the best tests to determine the presence and extent of cardiac involvement (discussed in detail later).

\section{Electrocardiogram}

A resting ECG is an appropriate screening test in all patients with sarcoidosis. ${ }^{4,8}$ Abnormalities on ECG (e.g., conduction disturbances, arrhythmias, or nonspecific ST and T-wave changes) have been noted in 20 to $31 \%$ of sarcoid patients. ${ }^{11,16,82,83}$ In one necropsy study, $42 \%$ of patients with mild cardiac involvement (microscopically evident granulomas) and $75 \%$ of patients with severe involvement (gross evidence of cardiac granulomas or infiltration at necropsy) had arrhythmias or conduction disturbances. ${ }^{16}$ However, resting ECGs are insensitive for detecting cardiac involvement; further, the clinical significance of nonspecific ECG abnormalities is unclear. Signal-averaged ECG may improve sensitivity ${ }^{84}$ In addition, specific ECG characteristics may be useful diagnostically. In a study of 112 patients with pulmonary sarcoidosis and possible cardiac symptoms, ECG characteristics were assessed. ${ }^{85}$ Of the 52 subjects eventually diagnosed with cardiac sarcoid, fragmented QRS (fQRS) was noted in 39 (75\%) compared with 21 of $60(35 \%)$ patients without cardiac involvement $(p>0.01) .{ }^{85}$ Right or left BBBs were more prevalent in patients with cardiac involvement compared with those without (right BBB: 23.1 vs. $6.7 \%, p=0.016$; left BBB: 3.8 vs. $1.7 \%, p=0.6$ ). QRS duration was significantly associated with cardiac involvement after exclusion of those with BBB $(93.5 \pm 10.6$ vs. $88 \pm$ $11 \mathrm{~ms} ; p=0.04)$. ECC findings of fQRS or BBB were cited in $90.4 \%$ of patients with cardiac involvement compared with $36.7 \%$ sarcoid patients without cardiac involvement $(p$ $<0.01)$.

Twenty-four hours Holter monitoring and exercise ECGs can detect abnormalities (e.g., tachyarrhythmias or heart block) even when resting ECGs are normal. ${ }^{22,83,86,87}$ Any 
abnormality on ECG or Holter monitor should be further evaluated by echocardiography ${ }^{11,13,88}$ or other imaging studies (discussed later).

\section{Echocardiography}

Doppler echocardiography (DE) is nonspecific, but is invaluable to assess cardiac chamber(s) size and function in patients with suspected or confirmed myocardial sarcoidosis. ${ }^{11,24}$ In early studies, abnormalities on DE were detected in 14 to $41 \%$ of patients with sarcoidosis, even in the absence of ECG abnormalities and clinical symptoms. ${ }^{9,11,13,88,89}$ Salient abnormalities include: global or focal hypokinesis or dyskinesia; wall motion abnormalities; chamber enlargement; ventricular wall thinning or aneurysms; ventricular dilatation or hypertrophy; depressed ejection fraction; diastolic dysfunction; valvular regurgitation; papillary muscle dysfunction; and pericardial effusions. ${ }^{24,88,90}$ In some cases, macroscopic areas of bright echoes were noted, reflecting granulomatous inflammation, ${ }^{62}$ described as a "speckled or snowstorm pattern." 22 Wall thinning or thickening of the IVS localized to the basal portion is characteristic of sarcoidosis. ${ }^{91,92}$ Yazaki et al reported DE findings from 15 patients with cardiac sarcoidosis and 30 patients with idiopathic dilated cardiomyopathy. ${ }^{24}$ Thinning $(<7 \mathrm{~mm})$ or thickening (> $13 \mathrm{~mm}$ ) of the ventricular wall (typically in the IVS) were noted in 11 of $15(73 \%)$ patients with cardiac sarcoidosis (73\%). Heart block was noted on ECG in all 11 patients. By contrast, only $17 \%$ of patients with idiopathic dilated cardiomyopathy had abnormal wall thickness. Interestingly, ${ }^{201}$ thallium scans, performed in 14 patients with cardiac sarcoidosis in that study, revealed perfusion defects in 13 (93\%) patients. ${ }^{24}$ Echocardiography alone is not sensitive to detect early myocardial sarcoid lesions ${ }^{8,11}$ but is noninvasive and a relatively inexpensive way to assess and follow cardiac size and function.

\section{Radionuclide Scans}

Radionuclide scans are integral to the diagnosis of cardiac sarcoidosis. Beginning in the 1970s and 1980s, gallium ${ }^{67}\left(\mathrm{Ga}^{67}\right)$ citrate $^{75,93-96}$ and thallium ${ }^{201}\left(\mathrm{Tl}^{201}\right)$ scans ${ }^{95,96}$ were used to diagnosis and follow cardiac sarcoidosis. In sentinel studies, thallium ${ }^{201}$ scanning was found to be superior to echocardiography to diagnose cardiac sarcoidosis. $9,10,12,75,97-99$ Tellier et al described a phenomenon of "reverse distribution" in cardiac sarcoidosis. ${ }^{10}$ Perfusion defects were noted on $\mathrm{Tl}^{201}$ scans at rest in 16 patients with cardiac sarcoidosis; the perfusion defects improved or completely resolved in 13 of 16 patients with exercise or dipyridamole. Subsequent studies affirmed that perfusion defects noted at rest in cardiac sarcoidosis disappeared or decreased in size following exercise or infusions of dipyridamole or adenosine. 9,93 This differs from coronary artery disease, in which defects at rest worsen or fail to improve with exercise, dipyridamole, or adenosine. ${ }^{10,97,98,100}$ Segmental areas of decreased $\mathrm{Tl}^{201}$ uptake are believed to correspond to areas of fibrosis or granulomatous replacement. $^{12}$

Refinements in techniques and radioisotopes, including the combination of $\mathrm{Tl}^{201}$ and $\mathrm{Ga}^{67}$ scanning with single photon emission CT (SPECT) ${ }^{75,95,96,101-103},{ }^{99}$ technetium $\left(\mathrm{Tc}^{99}\right.$ )

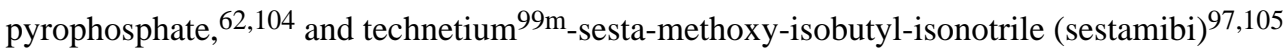
were evaluated. In one study, $\mathrm{Tl}^{201}$ and $\mathrm{Tc}^{99}$-setamibi SPECT scans were performed in 37 
patients with sarcoidosis and suspected cardiac involvement (i.e., all had chest pain, LV failure, or abnormal ECGs). ${ }^{97} \mathrm{Tc}^{99 \mathrm{~m}}$-sestamibi was more sensitive than $\mathrm{Tl}^{201}$ in detecting defects (65 vs. $46 \%$ ), and the abnormalities seen were larger with $\mathrm{Tc}^{99 \mathrm{~m}}$ than with $\mathrm{Tl}^{201} .{ }^{97}$ After dipyridamole, $\mathrm{Tc}^{99 \mathrm{~m}}$ sestamibi defects improved in 21 of 24 patients $(88 \%)$ and did not change in 3. Repeat SPECT scans were performed in 13 patients after 3 months of CS therapy; sestamibi defects resolved completely in 8 , improved in 4 , and were stable in 1 . Further, these was a high linear correlation between the improvement of defects after dipyridamole infusion and their improvement after CS therapy $(r=0.85, p<0.001)$.

Other radionuclide agents that have been studied in cardiac sarcoidosis include iodine ${ }^{123}$. labeled 15-(p-iodophenyl)-3R,S-methylpentadecanoic acid (BMIPP) ${ }^{106}$; iodine ${ }^{123}$-metaiodobenzylguianidine (MIBG),${ }^{107}$ indium ${ }^{111}$-labeled antimyosin antibody, ${ }^{108}$ but data are sparse and we see no role for those agents.

The above studies are useful primarily for historical interest. Currently, 18Ffluorodeoxyglucose $\left({ }^{18} \mathrm{FDG}\right)$-PET/CT ${ }^{76,78}$ and gadolinium-enhanced MRI scans ${ }^{77}$ have supplanted other radionuclide scans to diagnose cardiac sarcoidosis.

\section{Positron Emission Tomography/Computed Tomography}

PET/CT with ${ }^{18} \mathrm{FDG}$ has become a key technique to diagnose active cardiac sarcoidosis ${ }^{78,109-112}$ (Figs. 2-6). ${ }^{18}$ FDG-PET/CT has been used to diagnose and "stage" sarcoidosis involvement in thoracic and extrathoracic sites. ${ }^{113-116}$ Increased update of ${ }^{18} \mathrm{FDG}$ occurs within activated leukocytes, macrophages, and CD4+ T lymphocytes, major components of granulomas. ${ }^{117}$ The specificity of PET as a diagnostic tool relies on the suppression of normal myocyte uptake of glucose. For this reason, prolonged fasting (> 12 hours), ${ }^{118,119}$ fatty acid loading, and heparin are commonly used before imaging to suppress myocardial glucose metabolism in favor of oxidation of free fatty acids. ${ }^{120}$ PET scans may show different patterns of diffuse and focal uptake (Fig. 2). ${ }^{121}$ Patchy and focal uptake patterns are most specific for cardiac sarcoidosis (Figs. 4-6).

In pulmonary sarcoidosis, increased update on ${ }^{18} \mathrm{FDG}$ correlated with clinical activity of disease. ${ }^{113-116}$ Further, ${ }^{18}$ FDG-PET/CT was a sensitive marker of disease activity in patients with extrapulmonary sarcoidosis. ${ }^{115}$ In 2006, Nishiyama et al reported that ${ }^{18}$ FDG-PET/CT was more sensitive than $\mathrm{Ga}^{67}$ scans, particularly in extrapulmonary sarcoidosis. ${ }^{111} \mathrm{In}$ addition, several studies showed that PET/CT was more sensitive than $\mathrm{Ga}^{67118,122}$ or $\mathrm{Tl}^{201}$ scans to diagnose cardiac sarcoidosis. ${ }^{122,123}$ Japanese investigators retrospectively evaluated 17 patients with cardiac sarcoidosis. ${ }^{123}$ Increased ${ }^{18}$ FDG uptake was noted in 14 of 17 patients, whereas $\mathrm{Ga}^{67}$ scans were abnormal in only three patients. The largest review on PET/CT to diagnose cardiac sarcoidosis was published in 2012 by Youssef et al. ${ }^{79}$ In this study, a meta-analysis was performed on all studies relevant to ${ }^{18}$ FDG-PET/CT to diagnose cardiac sarcoidosis. Seven studies were evaluated, including patients from the Cardiac FDGPET Registry Study which comprised patients referred for ${ }^{18}$ FDG -PET/CT in Ontario, Canada. ${ }^{79}$ Total 164 patients were included in the analysis; the range of sensitivities and specificities for ${ }^{18}$ FDG-PET/CT were 79 to $100 \%$ and 38 to $100 \%$, respectively. Pooled estimates demonstrated a sensitivity of $89 \%$ and specificity of $78 \%$ (Table 2). 
Serial PET-CT scans may be useful to evaluate response to therapy in cardiac sarcoidosis. ${ }^{112,123}$ Improvement in PET scans (i.e., reduction in ${ }^{18}$ FDG uptake) has been noted following therapy with CSs. ${ }^{112,122-124}$ In an early study, 16 patients with sarcoidosis underwent ${ }^{18} \mathrm{FDG}-\mathrm{PET} / \mathrm{CT},{ }^{67} \mathrm{Ga}$, and ${ }^{201} \mathrm{Tl}$ scans; cardiac sarcoidosis was documented clinically or by EMBs in 10 patients. ${ }^{12218}$ FDG uptake was increased in all 10 patients; ${ }^{99 \mathrm{~m}} \mathrm{Tc}$ and ${ }^{67} \mathrm{Ga}$ scans were abnormal in $8(80 \%)$ and $5(50 \%)$ patients, respectively. In a subsequent study, ${ }^{18}$ FDG-PET/CT scans were performed in 17 patients with cardiac sarcoidosis. ${ }^{123}{ }^{18}$ FDG uptake in the heart was increased in 14/17 (82\%); by contrast, abnormal myocardial uptake was noted in only $6(35 \%)$ and $3(18 \%)$ patients with $\mathrm{Tl}^{201}$ or $\mathrm{Ga}^{67}$ scans, respectively. Increased ${ }^{18} \mathrm{FDG}$ uptake was observed most frequently in the basal and mid-anteroseptal lateral wall of the LV; involvement of the apex was rare. PET/CT scans were repeated in seven patients after 1 month of CS therapy; ${ }^{18} \mathrm{FDG}$ defects disappeared entirely in five and improved in two. ${ }^{123}$ Currently, ${ }^{18}$ FDG-PET/CT is often combined with MRI to diagnose cardiac sarcoid ${ }^{76}$ to provide complementary information. Although PET may be more sensitive for early phases of inflammation, MRI is more specific for later phases of scar formation. ${ }^{125}$ Recently, Blankstein et al demonstrated that focal perfusion detection and ${ }^{18}$ FDG uptake on PET in patients with suspected cardiac sarcoidosis provided additional prognostic value for death and VT beyond Japanese clinical criteria. ${ }^{119}$ In this study, ${ }^{18}$ FDG-PET scans were per formed in 118 patients with known or suspected cardiac sarcoidosis. PET scans were abnormal in $71(60 \%)$. Over a median follow-up of 1.5 years, there were 31 (26\%) adverse events (AE) (i.e., 27 VT and 8 deaths). Cardiac PET findings were predictive of AE; the presence of both a perfusion defect and abnormal ${ }^{18}$ FDG update (29\% of patients) was associated with a hazard ratio of 3.9 ( $p<$ 0.01 ) and remained significant after adjusting for LV ejection fraction (LVEF) and clinical criteria. $^{119}$

Although ${ }^{18}$ FDG-PET is a pivotal test in patients with cardiac sarcoidosis for initial diagnosis and follow-up, pitfalls have been noted including: (1) physiological uptake of ${ }^{18}$ FDG in myocardium may be found in healthy subjects; (2) normal myocardium may exhibit increased physiologic uptake on the basal and lateral LV walls; (3) pulmonary hypertension increases RV and IVS ${ }^{18}$ FDG update because of the mechanical overload; and (4) nonspecific ${ }^{8}$ FDG uptake may be observed in patients with nonsarcoid dilated cardiomyopathies. ${ }^{8}$

\section{Gadolinium-Enhanced Cardiac MRI}

Gadolinium-enhanced cardiac MRI (CMR) may identify regional differences in enhancement between diseased and normal myocardial tissue. ${ }^{126,127}$ Gadolinium contrast media has a molecular size that distributes rapidly into the extracellular space of the myocardium and is excluded from normal myocardial cells. In the setting of fibrosis, the extracellular space is larger than in normal myocardium, accounting for the regional enhancement of myocardial scar tissue. ${ }^{128,129}$ In cardiac sarcoidosis, gadolinium may demonstrate diffuse or focal enhancement, particularly in the myocardial wall or subepicardial region, thought to be related to edema associated with inflammation and infiltration from granuloma formation in addition to myocardial scar ${ }^{126,127}$ (Fig. 7). 
Early experience with CMR in cardiac sarcoidosis showed this imaging modality to be superior to echocardiography. ${ }^{130-136}$ In a sentinel report, CMR was performed in 16 patients with suspected cardiac sarcoidosis. ${ }^{131}$ Localized enhancement of signal intensity on T1weighted images was noted in the LV in eight patients (50\%) indicative of interstitial edema or scarring. Importantly, echocardiograms were abnormal in only two patients. After 1 month of CS treatment, MRI signal intensity was markedly diminished in all eight patients. ${ }^{131}$ Vignaux et al prospectively performed $\mathrm{Tl}^{201}$ scans and gadolinium-enhanced MRI in 40 patients with sarcoidosis. ${ }^{137}$ CMRs were abnormal in all 5 with cardiac sarcoidosis and in 17 of 31 (54\%) with multiorgan sarcoidosis but without cardiac symptoms. Thus, subclinical myocardial involvement may be detected by CMR even in patients lacking cardiac symptoms.

In 2005, Smedema et al reported 58 patients with biopsyproven pulmonary sarcoidosis; 12 (21\%) had cardiac sarcoidosis. ${ }^{138}$ All 58 patients had both $\mathrm{Tl}^{201}$ scans and CMR. CMR revealed late gadolinium enhancement in 19 patients, mostly involving basal and lateral segments. In 8 of the 19 patients, $\mathrm{Tl}^{201}$ scintigraphy was normal. The sensitivity and specificity of CMR were 100\% (confidence interval [CI], 78-100\%) and 78\% (CI, 64-89\%), respectively. Positive and negative predictive values were 55 and $100 \%$, respectively; overall accuracy was $83 \% .^{138}$

In 2008, Ichinose et al reported 40 patients with sarcoidosis; 11 had cardiac involvement. ${ }^{139}$ Gadolinium myocardial enhancement was noted in 10 of 11 patients with cardiac sarcoidosis but in none of the 29 patients without cardiac sarcoidosis. Enhancement was seen most frequently in the subepicardial and mid-myocardial layers $(p<0.001) .{ }^{139}$ In two studies comprising five patients with cardiac sarcoidosis, delayed enhancement in MRI was evident, mainly distributed in the mid- to epimyocardium. ${ }^{140,141}$ Yoshida et al performed EMBs and CMR in 17 patients with cardiac sarcoid diagnosed according to the Japanese Ministry guidelines. ${ }^{142}$ CMR demonstrated findings consistent with cardiac sarcoidosis in 13 of 17 (76\%) patients, whereas EMB were positive in only 6 of 17 (35\%). Sensitivities and specificities were 76 and 92\%, respectively, with CMR, as compared with 35 and 100\%, respectively, with EMB. ${ }^{142}$ Multicontrast late phase gadolinium enhancement MRI may exhibit improved sensitivity for cardiac sarcoidosis. ${ }^{78}$ Cardiac sarcoid lesions appears as patchy or focal hyperenhancement patterns in the LV free wall, papillary muscles, or IVS. ${ }^{78}$ Upon review of numerous published studies, sensitivity of gadolinium-enhanced CMR for cardiac sarcoidosis ranges from 75 to $>95 \%$, with specificities of approximately 75 to $80 \% .^{110,126,138,143,144}$

In addition to providing a valuable diagnostic tool for cardiac sarcoidosis, delayed enhancement on CMR (possibly reflecting the absence of viable myocytes in collagenous scar) may serve as a prognostic indicator for severity of disease. ${ }^{140,141,145}$ In a review of 61 consecutive patients with cardiac sarcoidosis seen in the Netherlands from 2002 to 2012, CMR was performed in 37 patients. ${ }^{145}$ Delayed enhancement on MRI was noted in 26 patients. Compared with patients without delayed enhancement, there was a trend to a higher rate of VA ( 29 vs. $0 \%, p=0.12$ ) and higher rate of composite clinical endpoint (i.e., VA, heart failure hospitalization, or cardiovascular death) (41 vs. $0 \%, p<0.05) .{ }^{145}$ In a recent study of 19 Japanese patients with cardiac sarcoidosis, the total number of affected segments 
on CMR correlated with duration of sarcoidosis in patients with onset in extracardiac sites ( $p$ $=0.005)$ as well as LVEF and LV diastolic volume. ${ }^{141}$ All patients with LVEF < 30\% had both subepicardial and transmural lesions.

Serial CMR may be valuable to follow the course of cardiac sarcoidosis. ${ }^{131}$ However, until recently, CMR could not be done in patients with pacemakers or implantable cardioverterdefibrillators (ICDs). The recent development of MRI-compatible pacemakers and pacemaker leads ${ }^{146}$ has made it possible to perform serial CMR even after ICD placement. ${ }^{144}$ In addition, we have developed a protocol for device artifact reduction at our institution to optimize the ability to interpret delayed enhancement images in patients with ICDs. ${ }^{147}$

\section{Coronary Angiography}

Coronary angiographies are often performed in patients with suspected cardiac sarcoidosis to exclude atherosclerotic coronary artery disease. Coronary angiograms are typically normal, but wall motion abnormalities may be observed on ventriculograms. ${ }^{148}$ Rarely, vascular filling defects due to granulomatous vasculitis ${ }^{66}$ have been described.

\section{What Is the Role of Endomyocardial Biopsies?}

Transvenous right ventricular EMBs have been used to diagnose cardiac sarcoidosis, particularly when multisystem disease is not evident, ${ }^{149}$ but sensitivity is low (19$32 \%) .{ }^{28,72,90,150}$ The presence of granulomas on histologic samples confirms the diagnosis $^{41,149}$ (Fig. 1E). Other histopathologic findings (e.g., myocardial interstitial fibrosis; heart muscle disarrangement and fragmentation; inflammatory mononuclear cell infiltrates) ${ }^{28,41,151}$ may support the diagnosis of sarcoidosis, but are nonspecific. In two series of patients with probable cardiac sarcoidosis, the yield of EMB was only 19\% (5 of $26)^{150}$ and $22 \%$ (4 of 18), respectively. ${ }^{28}$ In a recent study of 52 patients with cardiac sarcoidosis seen at one institution, EMB demonstrated sarcoidosis in 10 of $31(32 \%)$ patients at initial biopsy. ${ }^{72}$ The diagnosis was established in 7 additional patients by repeat EMB (targeted by cardiac imaging); in 11 patients, the diagnosis of cardiac sarcoidosis was affirmed by sampling ${ }^{18}$ FDG -PET (+) mediastinal lymph nodes. Importantly, the diagnosis of cardiac sarcoidosis was established in four patients after cardiac transplantation and in one at necropsy who died suddenly.

The low yield of biopsy likely reflects sampling error. ${ }^{2,90,151}$ Cardiac sarcoidosis involves the myocardium in a patchy fashion, particularly in early or mild disease. ${ }^{2}$ EMBs are obtained mostly from the RV free wall and apex of the IVS, whereas granulomas more commonly are found in the LV free wall or base of the septum. ${ }^{15}$ Given the low yield of $\mathrm{EMB},{ }^{72,150,151}$ and potential morbidity, ${ }^{97,152,153}$ we do not recommend routine EMB to confirm myocardial involvement provided other objective measures of cardiac dysfunction or abnormality are substantiated (particularly by radionuclide techniques). Sarcoid patients with cardiac dysfunction or ECG aberrations and no alternative etiology should be presumed to have cardiac involvement, even when EMB are nondiagnostic. 


\section{Differential Diagnosis and Mimics of Cardiac Sarcoidosis}

The differential diagnosis of cardiac sarcoidosis is complex as the clinical signs (if present) and features on imaging studies may overlap with other cardiac disorders. The differential diagnosis includes: dilated cardiomyopathy (all causes), ${ }^{18,24}$ arrhythmogenic right ventricular cardiomyopathy (ARVC), ${ }^{154-156}$ idiopathic giant cell myocarditis, ${ }^{157,158}$ lymphocytic myocarditis, ${ }^{159}$ connective tissue disease, ${ }^{160}$ vasculitis (especially Takayasu arteritis ${ }^{161}$ and Wegener granulomatosis ${ }^{162}$ ), amyloidosis, ${ }^{163}$ dengue fever, ${ }^{164}$ Chagas disease, ${ }^{165}$ and other infectious causes (e.g., rheumatic fever, syphilis, fungal infections, and tuberculosis $[\mathrm{TB}])^{8}$

When cardiomyopathy is present, the most common diagnoses (in addition to cardiac sarcoid) include: ARVC; ischemic cardiomyopathy (ICM); nonischemic dilated cardiomyopathy (NICM); infiltrative cardiomyopathies (e.g., amyloidosis); and RV infarction. When VA are the presenting feature, distinguishing cardiac sarcoidosis from other entities may be difficult. Because sarcoidosis can present with isolated RV or LV involvement, or both, 12-lead ECG morphology cannot differentiate cardiac sarcoidosis from other scar-related re-entrant VA. ${ }^{155}$ Twelve-lead morphology of arrhythmias of RV origin can be similar to either idiopathic RV outflow tract (RVOT) arrhythmias or those secondary to ARVC. ${ }^{155}$

When the clinical presentation is isolated conduction system disease (first, second, or third degree heart block or BBB), the differential includes age-related conduction system disease, Lyme disease, Brugada syndrome, and myocarditis. QRS fractionation can occur with sarcoidosis and is associated with delayed enhancement on CMR. ${ }^{166} \mathrm{QRS}$ fractionation can be seen in several other pathologic structural conditions such as ICM, NICM, and ARVC. It can also been found in primary electrical diseases of the RV such as Brugada syndrome. ${ }^{167,168}$ Further, RV conduction delay related to sarcoidosis could be confused with a Brugada pattern ECG. Brugada syndrome is thought to be a primary electrical disorder; however, these patients may have underlying structural abnormalities of the RVOT. ${ }^{169}$ Further discussion of the entities included in the differential diagnosis is beyond the scope of this article.

EMB demonstrating nonnecrotizing granulomata is the gold standard to diagnose cardiac sarcoidosis, but its low sensitivity limits the clinical applicability of EMB. Radionuclide and MRI are critical to narrow the diagnosis. In particular, differentiating sarcoidosis from ARVC can be difficult. ${ }^{170}$ Many patients who met task force criteria for ARVC were ultimately found to have biopsy-proven cardiac sarcoidosis. MRI criteria have been assessed to help differentiate these two entities, but sensitivity and specificity are again limited. ${ }^{170,171}$

\section{Is There a Role for Routine Screening for Cardiac Sarcoidosis?}

Mehta et al screened 62 ambulatory patients with sarcoidosis for possible cardiac involvement by ECG, Holter monitoring, DE, and cardiac symptoms (i.e., palpitations, syncope, or presyncope). ${ }^{172}$ Those with positive symptoms or screening tests underwent MRI and PET scans. Overall, 24 (39\%) had cardiac sarcoid. Patients with cardiac sarcoidosis had more cardiac symptoms than those without cardiac involvement (46 vs. 5\%, 
respectively; $p<0.001$ ), and were more likely to have abnormal Holter monitor (50 vs. 3\%, respectively; $p<0.001$ ) and DE (25 vs. $5 \%$, respectively; $p=0.02$ ). Electrophysiological testing was performed in 17 patients, 2 of whom had abnormal findings and received ICD. During almost 2 years of follow-up, no patients died or had VA that triggered ICD therapy or had heart failure. ${ }^{172} \mathrm{In}$ an earlier article, these authors evaluated a cohort of 76 patients with biopsy-proven systemic sarcoidosis without cardiac symptoms, but with evidence of cardiac sarcoidosis by PET/CT or MRI scans. ${ }^{173}$ All patients underwent programmed electric stimulation (PES) of the ventricle. Sustained VA were induced in eight (11\%) subjects; all eight received an ICD. None of 68 noninducible patients received an ICD. All patients were followed up for survival and arrhythmic events. Initial LVEF (by DE) was lower in patients with inducible VA (36.4 vs. 55.8\%; $p<0.05$ ). Over a median follow-up of 5 years, six of eight patients in the group with inducible VA had further episodes of VA or died, compared with one death in the negative group $(p<0.0001) .{ }^{173}$ Finnish investigators described nine patients in whom VA (VT or ventricular fibrillation) was the presenting feature of sarcoidosis; EMBs were positive in eight. ${ }^{174}$ All patients received antiarrhythmics and ICDs; high-dose CS were given in eight. During follow-up (50 \pm 34 months), five patients underwent appropriate ICD therapies and nonsustained VT episodes were detected in four. Two developed incessant VT, treated by catheter ablation. One patient was referred for heart transplantation.

Since sudden death can occur even in asymptomatic patients with cardiac sarcoidosis, placement of ICDs is mandatory in any patient with cardiac sarcoidosis and a history of serious VA or inducible VT. The course of patients with cardiac sarcoidosis and negative PES (noninducible) appears to be benign, but additional studies are required to determine long-term prognosis and appropriate therapeutic management in these cases.

\section{Treatment of Cardiac Sarcoidosis}

The prognosis of symptomatic cardiac sarcoidosis is not well defined, but mortality rates of untreated cardiac sarcoidosis are high. ${ }^{2,19,24,25,45}$ Numerous publications (individual case reports and small series) cited favorable responses to CSs in patients with cardiac sarcoidosis, ${ }^{6,24,54,75,148,149,175}$ but randomized trials have not been done. Nonetheless, CS, alone or combined with additional immunosuppressive medications, remains the mainstay of treatment. ${ }^{8,176-179}$

In 1998, Yazaki et al cited 3- and 5-year survival rates of 50 and 37\% in a cohort of 15 Japanese patients with cardiac sarcoidosis (14 were treated with CS). ${ }^{24}$ In 2001, these investigators described 95 Japanese patients with cardiac sarcoidosis seen between 1984 and $1996 .^{25}$ The diagnosis was made at necropsy in 20 patients, none of whom had received CS. All 75 in whom the diagnosis was established antemortem were treated with CS. During the mean follow-up of 68 months, 29 of 75 patients (39\%) died of congestive heart failure and $11(15 \%)$ died suddenly. The 5-year survival rates (by Kaplan-Meier analysis) were $75 \%$ in the CS-treated patients compared with only $10 \%$ in autopsy cases (subjects had not been treated with CS). However, there were no significant differences in survival curves of patients treated with a high initial dose (>30 mg) or a low initial dose (> or $=30 \mathrm{mg}$ ) of prednisone. Another Japanese study cited a lower response rate to CS (48\%) among cardiac 
sarcoid patients compared with $>70 \%$ response for sarcoid patients with involvement of noncardiac sites. ${ }^{180}$ In a retrospective French study, 39 patients with cardiac sarcoidosis were treated with CS (initial dose prednisone $\sim 1 \mathrm{mg} / \mathrm{kg} /$ day); 13 also received another immunosuppressive agent (IA). ${ }^{42}$ The average duration of CS therapy was 43 months (range, 6-168 months). During long-term follow-up (average 58 months), $87 \%$ of the patients improved and 54\% were presumed cured. Importantly, no patient died suddenly. Two patients worsened, one of whom did not receive pharmacological therapy. During follow-up, nine patients relapsed. Upon relapse, prednisone dose was $<10 \mathrm{mg}$ /day in five patients; prednisone had been stopped in three patients. All nine relapses were treated with CS (alone, or combined with IA). Cures were noted in six of nine; three showed clinical and laboratory improvement. These data are too limited to comment on appropriate duration of CS therapy and/or when to initiate IA (or which agent).

Extent and severity of disease may influence therapeutic responsiveness. Kato et al described 40 patients with cardiac sarcoidosis, 20 of whom had AV block but normal cardiac function (LVEF > 50\%). In the subset of 20 patients with normal LV function, 7 were treated with CS and 13 were not treated. During a mean observation period of $79.4 \pm$ 39.9 months, none of 7 CS-treated patients died, whereas 2 of $13(15.4 \%)$ untreated patients died. ${ }^{175}$ Importantly, AV block resolved in 4 of 7 CS-treated patients, but did not resolve in any of the 13 untreated patients $(p<0.05)$. Although LVEF did not differ significantly between the treated and untreated groups at the time of initial evaluation (66.7 vs. 60.5), a marked decline in LVEF was noted in the untreated patients during follow-up (37.6 \pm $17.3 \%)$, but not in the treated group $(62.1 \pm 4.4 \%$; $p<0.005) .{ }^{25} \mathrm{VT}$ was not present at the initial assessment in any patient in either group. During follow-up, VT occurred in only 1 of 7 treated patients $(14.3 \%)$ compared with 8 of 13 untreated patients $(61.5 \% ; p<0.05)$. Sadek et al recently performed a meta-analysis of 10 publications that evaluated CS treatment of cardiac sarcoidosis. ${ }^{177}$ Among 57 patients with AV conduction disease treated with CS, $47.4 \%$ improved, whereas none of 16 untreated patients improved. ${ }^{177}$ Japanese investigators evaluated 31 patients with cardiac sarcoidosis with frequent PVCs (> 300/day); 14 had nonsustained VT (NSVT). ${ }^{181}$ All patients were treated with prednisone (initial dose $30 \mathrm{mg} /$ day). Overall, there was no difference in the number of PVCs or incidence of NSVT before or after CS therapy. However, in patients with LVEF > 35\%, a significant reduction in number of PVCs/24 hours (from 1,820 to 742) and prevalence of NSVT (from 41 to 6\%) was noted. Patients with LVEF $>35 \%$ had significantly higher prevalence of $\mathrm{Ga}^{67}$ uptake compared with patients with LVEF $<35 \%$. This suggests that CS may be effective in early, but not late, stages or cardiac sarcoidosis. ${ }^{181}$ Recently, these investigators reported 15 patients with cardiac sarcoidosis with advanced or complete AV block; all were treated with prednisone (initial dose $30 \mathrm{mg} /$ day) after placement of ICD. ${ }^{182}$ During a mean follow-up of 7.1 years, AV resolved to normal or first degree AV block in 7 of 15 patients. The "recovery" group showed a higher LVEF (69.4\%) compared with non-responders (LVEF $44.1 \%$ ). In the recovery group, advanced AV did not recur. Unfortunately, even with aggressive CS therapy, cardiac disease may progress, and may be fatal. ${ }^{5,176}$

Despite the lack of randomized trials, extensive clinical experience strongly supports aggressive treatment with CS for clinically evident cardiac sarcoidosis. ${ }^{8,42,176}$ However, the 
appropriate dose and duration of CS therapy, and the role of concomitant IAs, have not been defined. Further, failures (including deaths) with high-dose CS have been described. ${ }^{174,183,184}$ A variety of IA and immunomodulatory agents been used to treat pulmonary and extrapulmonary sarcoidosis (including CS-recalcitrant cases). ${ }^{179,185-187}$ However, experience with cardiac sarcoidosis is limited to anecdotal cases ${ }^{183,188-190}$ and small retrospective series. ${ }^{42}$ In a retrospective study from France, 11 patients were treated with IA (usually combined with CS); complete recovery was cited in 4; 6 improved; 1 failed. For specific IA, favorable responses were cited as follows: methotrexate (three of six); cyclophosphamide (six of eight); cyclosporine (two of three). Given the paucity of data, the optimal agent or agents to treat cardiac sarcoidosis, and appropriate duration of therapy, have not been elucidated. Our approach to treating cardiac sarcoidosis is outlined below.

\section{Our Approach to Treatment of Cardiac Sarcoidosis}

For patients with proven or suspected myocardial sarcoidosis, we initiate treatment with CS. Symptomatic patients or those with serious VA typically receive a 3-day pulse of intravenous methylprednisolone ( $500 \mathrm{mg}$ daily), followed by prednisone $40 \mathrm{mg} / \mathrm{day}$ for a minimum of 4 weeks. Prednisone is gradually tapered to a maintenance dose of $10 \mathrm{mg}$ by 6 months, but the rate of CS taper is variable depending on clinical status and the presence or absence of adverse effects. At 4 weeks, we $a d d$ an IA (typically azathioprine [AZA], but other agents such as methotrexate or cyclophosphamide could be considered. At 6 weeks, we add hydroxychloroquine $200 \mathrm{mg}$ bid. The rationale for triple drug therapy is not only to enhance efficacy but also as a steroid-sparing strategy. The duration of therapy depends on the individual case, but we typically maintain low-dose prednisone (5-10 mg daily), lowdose AZA (100 mg daily), and hydroxychloroquine $200 \mathrm{mg}$ once daily for a minimum of 2 to 3 years since relapses can be life threatening and may cause permanent damage. Clinical relapses of cardiac sarcoidosis require retreatment with high-dose CS (usually IV pulse methylprednisolone) and/or immunosuppressive or cytotoxic agents (Table 3).

For follow-up, serial DE at 3 months (to assess cardiac function and LVEF), PET/CT (at 3-6 months), and/or CMR (at 3-6 months) are appropriate. When patients have gone into complete remission, serial PET/CT and DE at 6-month intervals are reasonable.

\section{Adjunctive Therapy (Catheter Ablation, Antiarrhythmics, and Implantable Cardioverter-defibrillators)}

The predictive value of programmed electrical stimulation-induced VA and guided antiarrhythmic medical therapy is limited in cardiac sarcoidosis. ${ }^{191-194}$ Serious VT can develop even in patients in whom VT could not be induced 48,191 and in sarcoid patients responding to CS (as evidenced by resolution of abnormal myocardial uptake on ${ }^{67} \mathrm{Ga}$ or ${ }^{99} \mathrm{Tc}$ scintiscans). ${ }^{191}$ In one study, programmed ventricular stimulation was performed in 32 consecutive patients with cardiac sarcoidosis. ${ }^{48}$ ICDs were placed in all 12 patients with spontaneous or inducible sustained VT; the other 20 did not receive ICD. All 32 patients were followed up for the combined arrhythmic event end point of appropriate ICD therapies or sudden death. Mean length of follow-up to sustained VA or sudden death was $32 \pm 30$ months. Five of six patients with spontaneous sustained VA and four of six patients without 
spontaneous but with inducible sustained VA received appropriate ICD therapy. Importantly, no patient with an ICD died of a primary VA. Among patients with spontaneous or inducible sustained VA, mean survival from first appropriate ICD therapy or death or cardiac transplant was $60 \pm 46$ months; only 2 of 12 patients with ICD died or required cardiac transplant at study end. Unfortunately, 2 of 20 patients (10\%) with neither spontaneous nor inducible sustained VA who did not receive ICD experienced sustained VA or sudden death.

In addition, the efficacy of antiarrhythmic agents to treat cardiac sarcoidosis is variable and breakthroughs (including sudden death) can occur. ${ }^{91,135,195,196}$ Disease-specific therapy may reduce the requirement for antiarrhythmic therapy and catheter ablation in patients with recurrent monomorphic VT. ${ }^{49}$ In one series, seven patients with cardiac sarcoidosis had sustained VT; six had a LVEF $<45 \% .{ }^{90}$ All were treated with antiarrhythmic agents; five were treated with CS. However, two patients had sudden cardiac death and an additional four had recurrent VT 2 or more months after initiation of CS treatment.

Given the potential for serious VA and sudden death, all sarcoid patients with severe VA, heart block, or cardiomyopathy should be considered for ICD in addition to medical therapy. ${ }^{90,135,191,192,197-200}$ Currently, Society Guidelines cited primary prevention ICD implantation as a class IIA recommendation (level C) for patients with cardiac sarcoidosis. $^{201}$

In a recent study of 45 patients with cardiac sarcoidosis, the incidence of VA requiring ICD therapy was approximately $15 \%$ per year. Longer follow-up, LV systolic dysfunction, and complete heart block were associated with serious VA. A recent multicenter study (13 sites) followed 235 patients with cardiac sarcoidosis post-ICD placement. ${ }^{202}$ Overall, 85 of 234 (36.2\%) patients received an appropriate ICD therapy (shocks and/or antitachycardia pacing) and 67 of $226(29.7 \%)$ received an appropriate shock at $4.2 \pm 4.0$ years. However, 57 patients $(24.3 \%)$ received a total of 222 inappropriate shocks; further, $46 \mathrm{AE}$ occurred in 41 patients $(17.4 \%)$. Thus, patients with cardiac sarcoidosis and ICDs are a high risk for VA, but the rate of inappropriate shocks and device complications is not trivial.

\section{Cardiac Ablation}

Cardiac ablation may be efficacious in patients with persistent VT despite medical therapy. ${ }^{174,183,184,203,204}$ In one study of 42 patients with cardiac sarcoidosis, VT was not controlled despite medical therapy (CS, antiarrhythmics) and ICD in 9 patients. ${ }^{204}$ Endocardial or epicardial radiofrequency ablation resulted in decreased $(n=4)$ or complete elimination $(n=5)$ of VT in all patients. Arrhythmic events decreased from a mean of $271 \pm$ 363 episodes preablation to $4.0 \pm 9.7$ postablation. However, radiofrequency ablation is not consistently effective. Thachil et al reported 14 patients with sustained monomorphic VT (SMVT), mediastinal adenopathy, and abnormalities on PET-CT in the mid-myocardium consistent with scar \pm inflammation. ${ }^{49}$ Mediastinal lymphnode biopsies revealed nonnecrotizing granulomas in all 14 patients; 11 (79\%) had TB (79\%). All patients were treated with antiarrhythmics \pm radiofrequency ablation, yet SMVT recurred in $92 \%$. The addition of disease-specific therapy (for TB or sarcoidosis) ended further recurrences in 
$64 \%$. The reduction/disappearance of SMVT correlated with resolution of myocardial inflammation on serial PET/CT scans.

\section{Surgical Options}

Surgical resection of ventricular aneurysms may be necessary for management of refractory VT. ${ }^{2,67,70,205}$ Massive or recurrent pericardial effusions refractory to medical therapy 45,56 may require pericardiectomy or pericardial window. ${ }^{56}$

\section{Cardiac Transplantation}

Cardiac transplantation should be considered for patients with severe intractable heart failure refractory to medical therapy. ${ }^{206-210}$ In a recent review of 19 patients with cardiac sarcoidosis who underwent heart transplantation, 5-year posttransplant survival rate was $79 \%$, comparable to $83 \%$ 5-year survival among recipients transplanted for other indications. ${ }^{207}$ No patient had recurrent sarcoidosis in the cardiac allograft. Zaidi et al examined outcomes of 65 heart transplant recipients with cardiac sarcoidosis from 1987 to 2005 in the national UNOS (United Network for Organ Sharing) database. In that study, 1and 5-year survival rates were 87.7 and $80.5 \%$ compared with heart transplant recipients without sarcoidosis ( 84.5 and $70 \%$, respectively). ${ }^{211}$ Recurrent sarcoidosis has been described in cardiac allografts, ${ }^{209,212-215}$ but is uncommon $(<10 \%),{ }^{206,207}$ and may respond to intensification of CSs.

\section{References}

1. Iannuzzi MC, Rybicki BA, Teirstein AS. Sarcoidosis. N Engl J Med. 2007; 357(21):2153-2165. [PubMed: 18032765]

2. Fleming, H. Cardiac sarcoidosis. In: James, DG., editor. Sarcoidosis and other granulomatous disorders. Marcel Dekker; New York: 1994. p. 323-334.

3. Fleming HA. Sarcoid heart disease. Br Heart J. 1974; 36(1):54-68. [PubMed: 4818140]

4. Statement on sarcoidosis. Joint Statement of the American Thoracic Society (ATS), the European Respiratory Society (ERS) and the World Association of Sarcoidosis and Other Granulomatous Disorders (WASOG) adopted by the ATS Board of Directors and by the ERS Executive Committee, February 1999. Am J Respir Crit Care Med. 1999; 160(2):736-755. [PubMed: 10430755]

5. Johns CJ, Michele TM. The clinical management of sarcoidosis. A 50-year experience at the Johns Hopkins Hospital. Medicine (Baltimore). 1999; 78(2):65-111. [PubMed: 10195091]

6. Ayyala US, Nair AP, Padilla ML. Cardiac sarcoidosis. Clin Chest Med. 2008; 29(3):493-508. ix. [PubMed: 18539240]

7. Baughman RP, Teirstein AS, Judson MA, et al. Case Control Etiologic Study of Sarcoidosis (ACCESS) research group. Clinical characteristics of patients in a case control study of sarcoidosis. Am J Respir Crit Care Med. 2001; 164(10):1885-1889. Pt 1. [PubMed: 11734441]

8. Nunes H, Freynet O, Naggara N, et al. 2010; 31(4):428-441.

9. Kinney EL, Jackson GL, Reeves WC, Zelis R. Thallium-scan myocardial defects and echocardiographic abnormalities in patients with sarcoidosis without clinical cardiac dysfunction. An analysis of 44 patients. Am J Med. 1980; 68(4):497-503. [PubMed: 7369231]

10. Tellier P, Paycha F, Antony I, et al. Reversibility by dipyridamole of thallium-201 myocardial scan defects in patients with sarcoidosis. Am J Med. 1988; 85(2):189-193. [PubMed: 3400694]

11. Fahy GJ, Marwick T, McCreery CJ, Quigley PJ, Maurer BJ. Doppler echocardiographic detection of left ventricular diastolic dysfunction in patients with pulmonary sarcoidosis. Chest. 1996; 109(1):62-66. [PubMed: 8549220] 
12. Bulkley BH, Rouleau JR, Whitaker JQ, Strauss HW, Pitt B. The use of 201thallium for myocardial perfusion imaging in sarcoid heart disease. Chest. 1977; 72(1):27-32. [PubMed: 872650]

13. Burstow DJ, Tajik AJ, Bailey KR, DeRemee RA, Taliercio CP. Two-dimensional echocardiographic findings in systemic sarcoidosis. Am J Cardiol. 1989; 63(7):478-482. [PubMed: 2916434]

14. Perry A, Vuitch F. Causes of death in patients with sarcoidosis. A morphologic study of 38 autopsies with clinicopathologic correlations. Arch Pathol Lab Med. 1995; 119(2):167-172. [PubMed: 7848065]

15. Roberts WC, McAllister HA Jr, Ferrans VJ. Sarcoidosis of the heart. A clinicopathologic study of 35 necropsy patients (group 1) and review of 78 previously described necropsy patients (group 11). Am J Med. 1977; 63(1):86-108. [PubMed: 327806]

16. Silverman KJ, Hutchins GM, Bulkley BH. Cardiac sarcoid: a clinicopathologic study of 84 unselected patients with systemic sarcoidosis. Circulation. 1978; 58(6):1204-1211. [PubMed: 709777]

17. Virmani R, Bures JC, Roberts WC. Cardiac sarcoidosis; a major cause of sudden death in young individuals. Chest. 1980; 77(3):423-428. [PubMed: 7357947]

18. Bagwan IN, Hooper LV, Sheppard MN. Cardiac sarcoidosis and sudden death. The heart may look normal or mimic other cardiomyopathies. Virchows Arch. 2011; 458(6):671-678. [PubMed: 21298287]

19. Matsui Y, Iwai K, Tachibana T, et al. Clinicopathological study of fatal myocardial sarcoidosis. Ann N Y Acad Sci. 1976; 278:455-469. [PubMed: 1067031]

20. Hamzeh NY, Wamboldt FS, Weinberger HD. Management of cardiac sarcoidosis in the United States: a Delphi study. Chest. 2012; 141(1):154-162. [PubMed: 21737493]

21. Deng JC, Baughman RP, Lynch JP III. Cardiac involvement in sarcoidosis. Semin Respir Crit Care Med. 2002; 23(6):513-527. [PubMed: 16088647]

22. Sharma OP, Maheshwari A, Thaker K. Myocardial sarcoidosis. Chest. 1993; 103(1):253-258. [PubMed: 8417889]

23. Longcope WT, Freiman DG. A study of sarcoidosis; based on a combined investigation of 160 cases including 30 autopsies from The Johns Hopkins Hospital and Massachusetts General Hospital. Medicine (Baltimore). 1952; 31(1):1-132. [PubMed: 14899212]

24. Yazaki Y, Isobe M, Hiramitsu S, et al. Comparison of clinical features and prognosis of cardiac sarcoidosis and idiopathic dilated cardiomyopathy. Am J Cardiol. 1998; 82(4):537-540. [PubMed: 9723651]

25. Yazaki Y, Isobe M, Hiroe M, et al. Central Japan Heart Study Group. Prognostic determinants of long-term survival in Japanese patients with cardiac sarcoidosis treated with prednisone. Am J Cardiol. 2001; 88(9):1006-1010. [PubMed: 11703997]

26. Sekiguchi M, Yazaki Y, Isobe M, Hiroe M. Cardiac sarcoidosis: diagnostic, prognostic, and therapeutic considerations. Cardiovasc Drugs Ther. 1996; 10(5):495-510. [PubMed: 8950063]

27. Iwai K, Sekiguti M, Hosoda Y, et al. Racial difference in cardiac sarcoidosis incidence observed at autopsy. Sarcoidosis. 1994; 11(1):26-31. [PubMed: 8036339]

28. Sekiguchi M, Numao Y, Imai M, Furuie T, Mikami R. Clinical and histopathological profile of sarcoidosis of the heart and acute idiopathic myocarditis. Concepts through a study employing endomyocardial biopsy. I. Sarcoidosis. Jpn Circ J. 1980; 44(4):249-263. [PubMed: 7373823]

29. Tachibana T, Ohmori F, Ueda E. Clinical study on cardiac sarcoidosis. Ann N Y Acad Sci. 1986; 465:530-542. [PubMed: 3014961]

30. Gideon NM, Mannino DM. Sarcoidosis mortality in the United States 1979-1991: an analysis of multiple-cause mortality data. Am J Med. 1996; 100(4):423-427. [PubMed: 8610729]

31. Morimoto T, Azuma A, Abe S, et al. Epidemiology of sarcoidosis in Japan. Eur Respir J. 2008; 31(2):372-379. [PubMed: 17959635]

32. Iannuzzi MC. Genetics of sarcoidosis. Semin Respir Crit Care Med. 2007; 28(1):15-21. [PubMed: 17330189]

33. Takashige N, Naruse TK, Matsumori A, et al. Genetic polymorphisms at the tumour necrosis factor loci (TNFA and TNFB) in cardiac sarcoidosis. Tissue Antigens. 1999; 54(2):191-193. [PubMed: 10488747] 
34. Meyer T, Lauschke J, Ruppert V, Richter A, Pankuweit S, Maisch B. Isolated cardiac sarcoidosis associated with the expression of a splice variant coding for a truncated BTNL2 protein. Cardiology. 2008; 109(2):117-121. [PubMed: 17703092]

35. Valentonyte R, Hampe J, Huse K, et al. Sarcoidosis is associated with a truncating splice site mutation in BTNL2. Nat Genet. 2005; 37(4):357-364. [PubMed: 15735647]

36. Rybicki BA, Walewski JL, Maliarik MJ, Kian H, Iannuzzi MC, ACCESS Research Group. The BTNL2 gene and sarcoidosis susceptibility in African Americans and Whites. Am J Hum Genet. 2005; 77(3):491-499. [PubMed: 16080124]

37. Spagnolo P, Sato H, Grutters JC, et al. Analysis of BTNL2 genetic polymorphisms in British and Dutch patients with sarcoidosis. Tissue Antigens. 2007; 70(3):219-227. [PubMed: 17661910]

38. Suzuki H, Ota M, Meguro A, et al. Genetic characterization and susceptibility for sarcoidosis in Japanese patients: risk factors of BTNL2 gene polymorphisms and HLA class II alleles. Invest Ophthalmol Vis Sci. 2012; 53(11):7109-7115. [PubMed: 22991420]

39. Naruse TK, Matsuzawa Y, Ota M, et al. HLA-DQB $1 * 0601$ is primarily associated with the susceptibility to cardiac sarcoidosis. Tissue Antigens. 2000; 56(1):52-57. [PubMed: 10958356]

40. Grunewald J. Review: role of genetics in susceptibility and outcome of sarcoidosis. Semin Respir Crit Care Med. 2010; 31(4):380-389. [PubMed: 20665388]

41. Lagana SM, Parwani AV, Nichols LC. Cardiac sarcoidosis: a pathology-focused review. Arch Pathol Lab Med. 2010; 134(7):1039-1046. [PubMed: 20586635]

42. Chapelon-Abric C, de Zuttere D, Duhaut P, et al. Cardiac sarcoidosis: a retrospective study of 41 cases. Medicine (Baltimore). 2004; 83(6):315-334. [PubMed: 15525844]

43. Tavora F, Cresswell N, Li L, Ripple M, Solomon C, Burke A. Comparison of necropsy findings in patients with sarcoidosis dying suddenly from cardiac sarcoidosis versus dying suddenly from other causes. Am J Cardiol. 2009; 104(4):571-577. [PubMed: 19660614]

44. Stewart RE, Graham DM, Godfrey GW, Friedman HZ, Das SK, Shea MJ. Rapidly progressive heart failure resulting from cardiac sarcoidosis. Am Heart J. 1988; 115(6):1324-1326. [PubMed: 3376855]

45. Shammas RL, Movahed A. Sarcoidosis of the heart. Clin Cardiol. 1993; 16(6):462-472. [PubMed: 8358879]

46. Fleming HA, Bailey SM. Sarcoid heart disease. J R Coll Physicians Lond. 1981; 15(4):245-246. 249-253. [PubMed: 7320964]

47. Kim JS, Judson MA, Donnino R, et al. Cardiac sarcoidosis. Am Heart J. 2009; 157(1):9-21. [PubMed: 19081391]

48. Aizer A, Stern EH, Gomes JA, Teirstein AS, Eckart RE, Mehta D. Usefulness of programmed ventricular stimulation in predicting future arrhythmic events in patients with cardiac sarcoidosis. Am J Cardiol. 2005; 96(2):276-282. [PubMed: 16018857]

49. Thachil A, Christopher J, Sastry BK, et al. Monomorphic ventricular tachycardia and mediastinal adenopathy due to granulomatous infiltration in patients with preserved ventricular function. J Am Coll Cardiol. 2011; 58(1):48-55. [PubMed: 21700089]

50. Viles-Gonzalez JF, Pastori L, Fischer A, Wisnivesky JP, Goldman MG, Mehta D. Supraventricular arrhythmias in patients with cardiac sarcoidosis prevalence, predictors, and clinical implications. Chest. 2013; 143(4):1085-1090. [PubMed: 23667912]

51. Zipse MM, Sauer WH. Electrophysiologic manifestations of cardiac sarcoidosis. Curr Opin Pulm Med. 2013; 19(5):485-492. [PubMed: 23880704]

52. Yazaki, Y.; Hongo, M.; Hiroyoshi, Y., et al. Cardiac sarcoidosis in Japan: treatment and prognosis. In: Sekiguchi, M.; Richardson, PJ., editors. Prognosis and Treatment of Cardiomyopathy and Myocarditis. University of Tokyo Press; Tokyo: 1994. p. 341-353.

53. Zoneraich S, Gupta MP, Mehta J, Zoneraich O, Wessely Z. Myocardial sarcoidosis presenting as acute mitral insufficiency. Chest. 1974; 66(4):452-454. [PubMed: 4137859]

54. Desai MY, Fallert MA. Rapidly progressing congestive heart failure due to cardiac sarcoidosis involving papillary muscles: a case report and brief review of the literature. Cardiol Rev. 2003; 11(4):163-168. [PubMed: 12852793]

55. Raftery EB, Oakley CM, Goodwin JF. Acute subvalvar mitral incompetence. Lancet. 1966; 2(7459):360-365. [PubMed: 4161952] 
56. Israel RH, Poe RH. Massive pericardial effusion in sarcoidosis. Respiration. 1994; 61(3):176-180. [PubMed: 8047724]

57. Garrett J, O’Neill H, Blake S. Constrictive pericarditis associated with sarcoidosis. Am Heart J. 1984; 107(2):394. [PubMed: 6695675]

58. Shiff AD, Blatt CJ, Colp C. Recurrent pericardial effusion secondary to sarcoidosis of the pericardium. N Engl J Med. 1969; 281(3):141-143. [PubMed: 4239834]

59. Kinney E, Murthy R, Ascunce G, Donohoe R, Zelis R. Pericardial effusions in sarcoidosis. Chest. 1979; 76(4):476-478. [PubMed: 477439]

60. Gregor P, Widimsky P, Sladkova T, Petrikova J, Cervenka V, Visek V. Echocardiography in sarcoidosis. Jpn Heart J. 1984; 25(4):499-508. [PubMed: 6502935]

61. Verkleeren JL, Glover MU, Bloor C, Joswig BC. Cardiac tamponade secondary to sarcoidosis. Am Heart J. 1983; 106(3):601-603. [PubMed: 6881041]

62. Angomachalelis N, Hourzamanis A, Salem N, et al. Pericardial effusion concomitant with specific heart muscle disease in systemic sarcoidosis. Postgrad Med J. 1994; 70(Suppl 1):S8-S12. [PubMed: 7971654]

63. Barton JH, Tavora F, Farb A, Li L, Burke AP. Unusual cardiovascular manifestations of sarcoidosis, a report of three cases: coronary artery aneurysm with myocardial infarction, symptomatic mitral valvular disease, and sudden death from ruptured splenic artery. Cardiovasc Pathol. 2010; 19(4):e119-e123. [PubMed: 19502084]

64. Wait JL, Movahed A. Anginal chest pain in sarcoidosis. Thorax. 1989; 44(5):391-395. [PubMed: 2763237]

65. Lam CS, Tolep KA, Metke MP, Glockner J, Cooper LT Jr. Coronary sarcoidosis presenting as acute coronary syndrome. Clin Cardiol. 2009; 32(6):E68-E71. [PubMed: 19330817]

66. Ward EV, Nazari J, Edelman RR. Coronary artery vasculitis as a presentation of cardiac sarcoidosis. Circulation. 2012; 125(6):e344-e346. [PubMed: 22331924]

67. Jain A, Starek PJ, Delany DL. Ventricular tachycardia and ventricular aneurysm due to unrecognized sarcoidosis. Clin Cardiol. 1990; 13(10):738-740. [PubMed: 2257716]

68. Kosuge H, Noda M, Kakuta T, Kishi Y, Isobe M, Numano F. Left ventricular apical aneurysm in cardiac sarcoidosis. Jpn Heart J. 2001; 42(2):265-269. [PubMed: 11384087]

69. Marks A, Anderson MH, Harrison NK. Ventricular aneurysm secondary to sarcoid disease. Heart. 2004; 90(6):694. [PubMed: 15145887]

70. Lull RJ, Dunn BE, Gregoratos G, Cox WA, Fisher GW. Ventricular aneurysm due to cardiac sarcoidosis with surgical cure of refractory ventricular tachycardia. Am J Cardiol. 1972; 30(3): 282-287. [PubMed: 5044487]

71. Haraki T, Ueda K, Shintani H, Hayashi T, Taki J, Mabuchi H. Spontaneous development of left ventricular aneurysm in a patient with untreated cardiac sarcoidosis. Circ J. 2002; 66(5):519-521. [PubMed: 12030352]

72. Kandolin R, Lehtonen J, Graner M, et al. Diagnosing isolated cardiac sarcoidosis. J Intern Med. 2011; 270(5):461-468. [PubMed: 21535250]

73. Hiraga, H.; Iwai, K.; Hiroe, M.; Omori, F.; Sekiguchi, M.; Tachibana, T. Guidelines for Diagnosis of Cardiac Sarcoidosis: Study Report on Diffuse Pulmonary Diseases. The Japanese Ministry of Health and Ministry; Tokyo: 1993. p. 23-24.

74. Judson MA, Baughman RP, Teirstein AS, Terrin ML, Yeager H Jr, Defining organ involvement in sarcoidosis: the ACCESS proposed instrument. ACCESS Research Group. A Case Control Etiologic Study of Sarcoidosis. Sarcoidosis Vasc Diffuse Lung Dis. 1999; 16(1):75-86. [PubMed: 10207945]

75. Okayama K, Kurata C, Tawarahara K, Wakabayashi Y, Chida K, Sato A. Diagnostic and prognostic value of myocardial scintigraphy with thallium-201 and gallium-67 in cardiac sarcoidosis. Chest. 1995; 107(2):330-334. [PubMed: 7842756]

76. White JA, Rajchl M, Butler J, Thompson RT, Prato FS, Wisenberg G. Active cardiac sarcoidosis: first clinical experience of simultaneous positron emission tomography-magnetic resonance imaging for the diagnosis of cardiac disease. Circulation. 2013; 127(22):e639-e641. [PubMed: 23733970] 
77. Patel MR, Cawley PJ, Heitner JF, et al. Detection of myocardial damage in patients with sarcoidosis. Circulation. 2009; 120(20):1969-1977. [PubMed: 19884472]

78. Yang Y, Safka K, Graham JJ, et al. Correlation of late gadolinium enhancement MRI and quantitative T2 measurement in cardiac sarcoidosis. J Magn Reson Imaging. 2014; 39(3):609-616. [PubMed: 23720077]

79. Youssef G, Leung E, Mylonas I, et al. The use of 18F-FDG PET in the diagnosis of cardiac sarcoidosis: a systematic review and meta-analysis including the Ontario experience. J Nucl Med. 2012; 53(2):241-248. [PubMed: 22228794]

80. Dubrey SW, Falk RH. Diagnosis and management of cardiac sarcoidosis. Prog Cardiovasc Dis. 2010; 52(4):336-346. [PubMed: 20109603]

81. Akbar JJ, Meyer CA, Shipley RT, Vagal AS. Cardiopulmonary imaging in sarcoidosis. Clin Chest Med. 2008; 29(3):429-443. viii. [PubMed: 18539236]

82. Thunéll M, Bjerle P, Stjernberg N. ECG abnormalities in patients with sarcoidosis. Acta Med Scand. 1983; 213(2):115-118. [PubMed: 6837330]

83. Gibbons WJ, Levy RD, Nava S, et al. Subclinical cardiac dysfunction in sarcoidosis. Chest. 1991; 100(1):44-50. [PubMed: 2060390]

84. Schuller JL, Lowery CM, Zipse M, et al. Diagnostic utility of signalaveraged electrocardiography for detection of cardiac sarcoidosis. Ann Noninvasive Electrocardiol. 2011; 16(1):70-76. [PubMed: 21251137]

85. Schuller JL, Olson MD, Zipse MM, et al. Electrocardiographic characteristics in patients with pulmonary sarcoidosis indicating cardiac involvement. J Cardiovasc Electrophysiol. 2011; 22(11): 1243-1248. [PubMed: 21615816]

86. Suzuki T, Kanda T, Kubota S, Imai S, Murata K. Holter monitoring as a noninvasive indicator of cardiac involvement in sarcoidosis. Chest. 1994; 106(4):1021-1024. [PubMed: 7523035]

87. Thunell M, Bjerle P, Karp K, Stjernberg N. Exercise test in patients with sarcoidosis. The importance of repolarization disturbances. Acta Med Scand. 1988; 223(1):69-73. [PubMed: 3348104]

88. Lewin RF, Mor R, Spitzer S, Arditti A, Hellman C, Agmon J. Echocardiographic evaluation of patients with systemic sarcoidosis. Am Heart J. 1985; 110(1):116-122. Pt 1. [PubMed: 4013969]

89. Moiseyev SV, Kornev BM, Shatkovsky NP, Eventov AZ, Pisareva NA. Non-invasive diagnosis of cardiac sarcoidosis. Lancet. 1987; 2(8561):739-740. [PubMed: 2888959]

90. Winters SL, Cohen M, Greenberg S, et al. Sustained ventricular tachycardia associated with sarcoidosis: assessment of the underlying cardiac anatomy and the prospective utility of programmed ventricular stimulation, drug therapy and an implantable antitachycardia device. $\mathbf{J}$ Am Coll Cardiol. 1991; 18(4):937-943. [PubMed: 1894867]

91. Padilla, ML. Cardiac sarcoidosis. In: Baughman, RP., editor. Sarcoidosis. New York, NY: Informa USA: 2010. p. 515-551.

92. Angomachalelis N, Hourzamanis A, Vamvalis C, Gavrielides A. Doppler echocardiographic evaluation of left ventricular diastolic function in patients with systemic sarcoidosis. Postgrad Med J. 1992; 68(Suppl 1):S52-S56. [PubMed: 1409217]

93. Mañá J. Nuclear imaging. 67Gallium, 201thallium, 18F-labeled fluoro-2-deoxy-D-glucose positron emission tomography. Clin Chest Med. 1997; 18(4):799-811. [PubMed: 9413659]

94. Hirose Y, Ishida Y, Hayashida K, et al. Myocardial involvement in patients with sarcoidosis. An analysis of 75 patients. Clin Nucl Med. 1994; 19(6):522-526. [PubMed: 8062473]

95. Tawarahara K, Kurata C, Okayama K, Kobayashi A, Yamazaki N. Thallium-201 and gallium 67 single photon emission computed tomographic imaging in cardiac sarcoidosis. Am Heart J. 1992; 124(5):1383-1384. [PubMed: 1442515]

96. Taki J, Nakajima K, Bunko H, Ohguchi M, Tonami N, Hisada K. Cardiac sarcoidosis demonstrated by Tl-201 and Ga-67 SPECT imaging. Clin Nucl Med. 1990; 15(9):636-639. [PubMed: 2208885]

97. Le Guludec D, Menad F, Faraggi M, Weinmann P, Battesti JP, Valeyre D. Myocardial sarcoidosis. Clinical value of technetium-99m sestamibi tomoscintigraphy. Chest. 1994; 106(6):1675-1682. [PubMed: 7988183] 
98. Tellier P, Valeyre D, Nitenberg A, Foult JM, Bedig G, Battesti JP. Cardiac sarcoidosis: reversion of myocardial perfusion abnormalities by dipyridamole. Eur J Nucl Med. 1985; 11(6-7):201-204. [PubMed: 4076228]

99. Yamamoto N, Gotoh K, Yagi Y, et al. Thallium-201 myocardial SPECT findings at rest in sarcoidosis. Ann Nucl Med. 1993; 7(2):97-103. [PubMed: 8318353]

100. Haywood LJ, Sharma OP, Siegel ME, et al. Detection of myocardial sarcoidosis by thallium 201 imaging. J Natl Med Assoc. 1982; 74(10):959-964. [PubMed: 7143469]

101. Kurata C, Sakata K, Taguchi T, et al. SPECT imaging with Tl-201 and Ga-67 in myocardial sarcoidosis. Clin Nucl Med. 1990; 15(6):408-411. [PubMed: 2354580]

102. Tajima T, Naito T, Dohi Y, Miyamae T. Ga-67 and Tl-201 imaging in sarcoidosis involving the myocardium. Clin Nucl Med. 1981; 6(3):120-121. [PubMed: 7460456]

103. Nagatomo Y, Imamura T, Koiwaya Y, et al. Thallium-201 and gallium-67 myocardial scintigraphy for the evaluation of sarcoid involvement. Clin Nucl Med. 1987; 12(4):335-336. [PubMed: 3581617]

104. Forman MB, Sandler MP, Sacks GA, Kronenberg MW, Powers TA. Radionuclide imaging in myocardial sarcoidosis. Demonstration of myocardial uptake of technetium pyrophosphate- $99 \mathrm{~m}$ and gallium. Chest. 1983; 83(3):578-580. [PubMed: 6297857]

105. Eguchi M, Tsuchihashi K, Hotta D, et al. Technetium-99m sestamibi/tetrofosmin myocardial perfusion scanning in cardiac and noncardiac sarcoidosis. Cardiology. 2000; 94(3):193-199. [PubMed: 11279326]

106. Kaminaga T, Takeshita T, Yamauchi T, Kawamura H, Yasuda M. The role of iodine-123-labeled 15-(p-iodophenyl)-3R,S-methyl-pentadecanoic acid scintigraphy in the detection of local myocardial involvement of sarcoidosis. Int J Cardiol. 2004; 94(1):99-103. [PubMed: 14996482]

107. Matsuo S, Nakamura Y, Matsui T, Matsumoto T, Kinoshita M. Detection of denervated but viable myocardium in cardiac sarcoidosis with I-123 MIBG and Tl-201 SPECT imaging. Ann Nucl Med. 2001; 15(4):373-375. [PubMed: 11577764]

108. Knapp WH, Bentrup A, Ohlmeier H. Indium-111-labelled antimyosin antibody imaging in a patient with cardiac sarcoidosis. Eur J Nucl Med. 1993; 20(1):80-82. [PubMed: 8420786]

109. Tahara N, Tahara A, Nitta Y, et al. Heterogeneous myocardial FDG uptake and the disease activity in cardiac sarcoidosis. JACC Cardiovasc Imaging. 2010; 3(12):1219-1228. [PubMed: 21163450]

110. Matthews R, Bench T, Meng H, Franceschi D, Relan N, Brown DL. Diagnosis and monitoring of cardiac sarcoidosis with delayed-enhanced MRI and 18F-FDG PET-CT. J Nucl Cardiol. 2012; 19(4):807-810. [PubMed: 22466988]

111. Nishiyama Y, Yamamoto Y, Fukunaga K, et al. Comparative evaluation of 18F-FDG PET and 67Ga scintigraphy in patients with sarcoidosis. J Nucl Med. 2006; 47(10):1571-1576. [PubMed: 17015889]

112. Braun JJ, Kessler R, Constantinesco A, Imperiale A. 18F-FDG PET/ CT in sarcoidosis management: review and report of 20 cases. Eur J Nucl Med Mol Imaging. 2008; 35(8):15371543. [PubMed: 18418595]

113. Teirstein AS, Machac J, Almeida O, Lu P, Padilla ML, Iannuzzi MC. Results of 188 whole-body fluorodeoxyglucose positron emission tomography scans in 137 patients with sarcoidosis. Chest. 2007; 132(6):1949-1953. [PubMed: 17925421]

114. Mostard RL, Verschakelen JA, van Kroonenburgh MJ, et al. Severity of pulmonary involvement and (18)F-FDG PET activity in sarcoidosis. Respir Med. 2013; 107(3):439-447. [PubMed: 23261309]

115. Mostard RL, Vöö S, van Kroonenburgh MJ, et al. Inflammatory activity assessment by F18 FDGPET/CT in persistent symptomatic sarcoidosis. Respir Med. 2011; 105(12):1917-1924. [PubMed: 21899998]

116. Keijsers RG, Verzijlbergen EJ, van den Bosch JM, et al. 18F-FDG PET as a predictor of pulmonary function in sarcoidosis. Sarcoidosis Vasc Diffuse Lung Dis. 2011; 28(2):123-129. [PubMed: 22117503]

117. Sobic-Saranovic D, Artiko V, Obradovic V. FDG PET imaging in sarcoidosis. Semin Nucl Med. 2013; 43(6):404-411. [PubMed: 24094707] 
118. Okumura W, Iwasaki T, Toyama T, et al. Usefulness of fasting 18F-FDG PET in identification of cardiac sarcoidosis. J Nucl Med. 2004; 45(12):1989-1998. [PubMed: 15585472]

119. Blankstein R, Osborne M, Naya M, et al. Cardiac positron emission tomography enhances prognostic assessments of patients with suspected cardiac sarcoidosis. J Am Coll Cardiol. 2014; 63(4):329-336. [PubMed: 24140661]

120. Schatka I, Bengel FM. Advanced imaging of cardiac sarcoidosis. J Nucl Med. 2014; 55(1):99106. [PubMed: 24232870]

121. Ishimaru S, Tsujino I, Takei T, et al. Focal uptake on 18F-fluoro-2-deoxyglucose positron emission tomography images indicates cardiac involvement of sarcoidosis. Eur Heart J. 2005; 26(15):1538-1543. [PubMed: 15809286]

122. Okumura W, Iwasaki T, Ueda T, et al. Usefulness of 18F-FDG PET for diagnosis of cardiac sarcoidosis. Kaku igaku Jpn J Nucl Med. 1999; 36:341-348.

123. Yamagishi H, Shirai N, Takagi M, et al. identification of cardiac sarcoidosis with (13)N-NH(3)/ (18)F-FDG PET. J Nucl Med. 2003; 44(7):1030-1036. [PubMed: 12843216]

124. Takeda N, Yokoyama I, Hiroi Y, et al. Positron emission tomography predicted recovery of complete A-V nodal dysfunction in a patient with cardiac sarcoidosis. Circulation. 2002; 105(9): 1144-1145. [PubMed: 11877369]

125. Ohira H, Tsujino I, Ishimaru S, et al. Myocardial imaging with 18F-fluoro-2-deoxyglucose positron emission tomography and magnetic resonance imaging in sarcoidosis. Eur J Nucl Med Mol Imaging. 2008; 35(5):933-941. [PubMed: 18084757]

126. Vignaux O. Cardiac sarcoidosis: spectrum of MRI features. AJR Am J Roentgenol. 2005; 184(1): 249-254. [PubMed: 15615984]

127. Giesbrandt KJ, Bolan CW, Shapiro BP, Edwards WD, Mergo PJ. Diffuse diseases of the myocardium: MRI-pathologic review of cardiomyopathies with dilatation. AJR Am J Roentgenol. 2013; 200(3):W274-82. [PubMed: 23436872]

128. Ordovas KG, Higgins CB. Delayed contrast enhancement on MR images of myocardium: past, present, future. Radiology. 2011; 261(2):358-374. [PubMed: 22012903]

129. Serra JJ, Monte GU, Mello ES, et al. Images in cardiovascular medicine. Cardiac sarcoidosis evaluated by delayed-enhanced magnetic resonance imaging. Circulation. 2003; 107(20):e188e189s. [PubMed: 12777322]

130. Chandra M, Silverman ME, Oshinski J, Pettigrew R. Diagnosis of cardiac sarcoidosis aided by MRI. Chest. 1996; 110(2):562-565. [PubMed: 8697868]

131. Shimada T, Shimada K, Sakane T, et al. Diagnosis of cardiac sarcoidosis and evaluation of the effects of steroid therapy by gadolinium-DTPA-enhanced magnetic resonance imaging. Am J Med. 2001; 110(7):520-527. [PubMed: 11343665]

132. Doherty MJ, Kumar SK, Nicholson AA, McGivern DV. Cardiac sarcoidosis: the value of magnetic resonance imaging in diagnosis and assessment of response to treatment. Respir Med. 1998; 92(4):697-699. [PubMed: 9659541]

133. Eliasch H, Juhlin-Dannfelt A, Sjögren I, Terent A. Magnetic resonance imaging as an aid to the diagnosis and treatment evaluation of suspected myocardial sarcoidosis in a fighter pilot. Aviat Space Environ Med. 1995; 66(10):1010-1013. [PubMed: 8526825]

134. Matsuki M, Matsuo M. MR findings of myocardial sarcoidosis. Clin Radiol. 2000; 55(4):323325. [PubMed: 10767198]

135. Bajaj AK, Kopelman HA, Echt DS. Cardiac sarcoidosis with sudden death: treatment with the automatic implantable cardioverter defibrillator. Am Heart J. 1988; 116(2):557-560. Pt 1. [PubMed: 3400575]

136. Danias PG. Gadolinium-enhanced cardiac magnetic resonance imaging: expanding the spectrum of clinical applications. Am J Med. 2001; 110(7):591-592. [PubMed: 11343676]

137. Vignaux O, Dhote R, Duboc D, et al. Clinical significance of myocardial magnetic resonance abnormalities in patients with sarcoidosis: a 1-year follow-up study. Chest. 2002; 122(6):18951901. [PubMed: 12475823]

138. Smedema JP, Snoep G, van Kroonenburgh MP, et al. Evaluation of the accuracy of gadoliniumenhanced cardiovascular magnetic resonance in the diagnosis of cardiac sarcoidosis. J Am Coll Cardiol. 2005; 45(10):1683-1690. [PubMed: 15893188] 
139. Ichinose A, Otani H, Oikawa M, et al. MRI of cardiac sarcoidosis: basal and subepicardial localization of myocardial lesions and their effect on left ventricular function. AJR Am J Roentgenol. 2008; 191(3):862-869. [PubMed: 18716120]

140. Matoh F, Satoh H, Shiraki K, et al. The usefulness of delayed enhancement magnetic resonance imaging for diagnosis and evaluation of cardiac function in patients with cardiac sarcoidosis. $\mathrm{J}$ Cardiol. 2008; 51(3):179-188. [PubMed: 18522793]

141. Watanabe E, Kimura F, Nakajima T, et al. Late gadolinium enhancement in cardiac sarcoidosis: characteristic magnetic resonance findings and relationship with left ventricular function. $\mathbf{J}$ Thorac Imaging. 2013; 28(1):60-66. [PubMed: 23249970]

142. Yoshida A, Ishibashi-Ueda H, Yamada N, et al. Direct comparison of the diagnostic capability of cardiac magnetic resonance and endomyocardial biopsy in patients with heart failure. Eur J Heart Fail. 2013; 15(2):166-175. [PubMed: 23329703]

143. Cheong BY, Muthupillai R, Nemeth M, et al. The utility of delayed-enhancement magnetic resonance imaging for identifying non-ischemic myocardial fibrosis in asymptomatic patients with biopsy-proven systemic sarcoidosis. Sarcoidosis Vasc Diffuse Lung Dis. 2009; 26(1):39-46. [PubMed: 19960787]

144. Ishibashi K, Takeda M, Yamahara Y. Clinical utility of a magnetic resonance-conditional pacemaker in a patient with cardiac sarcoidosis. Intern Med. 2013; 52(12):1341-1345. [PubMed: 23774544]

145. Shafee MA, Fukuda K, Wakayama Y, et al. Delayed enhancement on cardiac magnetic resonance imaging is a poor prognostic factor in patients with cardiac sarcoidosis. J Cardiol. 2012; 60(6): 448-453. [PubMed: 22944174]

146. Wilkoff BL, Bello D, Taborsky M, et al. EnRhythm MRI SureScan Pacing System Study Investigators. Magnetic resonance imaging in patients with a pacemaker system designed for the magnetic resonance environment. Heart Rhythm. 2011; 8(1):65-73. [PubMed: 20933098]

147. Stevens SM, Tung R, Rashid S, et al. Device artifact reduction for magnetic resonance imaging of patients with implantable cardioverter-defibrillators and ventricular tachycardia: late gadolinium enhancement correlation with electroanatomic mapping. Heart Rhythm. 2014; 11(2):289-298. [PubMed: 24140812]

148. Ishikawa T, Kondoh H, Nakagawa S, Koiwaya Y, Tanaka K. Steroid therapy in cardiac sarcoidosis. Increased left ventricular contractility concomitant with electrocardiographic improvement after prednisolone. Chest. 1984; 85(3):445-447. [PubMed: 6697806]

149. Lorell B, Alderman EL, Mason JW. Cardiac sarcoidosis. Diagnosis with endomyocardial biopsy and treatment with corticosteroids. Am J Cardiol. 1978; 42(1):143-146. [PubMed: 677030]

150. Uemura A, Morimoto S, Hiramitsu S, Kato Y, Ito T, Hishida H. Histologic diagnostic rate of cardiac sarcoidosis: evaluation of endomyocardial biopsies. Am Heart J. 1999; 138(2):299-302. Pt 1. [PubMed: 10426842]

151. Ratner SJ, Fenoglio JJ Jr, Ursell PC. Utility of endomyocardial biopsy in the diagnosis of cardiac sarcoidosis. Chest. 1986; 90(4):528-533. [PubMed: 3757563]

152. Felker GM, Hu W, Hare JM, Hruban RH, Baughman KL, Kasper EK. The spectrum of dilated cardiomyopathy. The Johns Hopkins experience with 1,278 patients. Medicine (Baltimore). 1999; 78(4):270-283. [PubMed: 10424207]

153. Veinot JP. Diagnostic endomyocardial biopsy pathology: secondary myocardial diseases and other clinical indications - a review. Can J Cardiol. 2002; 18(3):287-296. [PubMed: 11907618]

154. Basso C, Thiene G, Corrado D, Angelini A, Nava A, Valente M. Arrhythmogenic right ventricular cardiomyopathy. Dysplasia, dystrophy, or myocarditis? Circulation. 1996; 94(5):983991. [PubMed: 8790036]

155. Dechering DG, Kochhäuser S, Wasmer K, et al. Electrophysiological characteristics of ventricular tachyarrhythmias in cardiac sarcoidosis versus arrhythmogenic right ventricular cardiomyopathy. Heart Rhythm. 2013; 10(2):158-164. [PubMed: 23070261]

156. Choo WK, Denison AR, Miller DR, Dempsey OJ, Dawson DK, Broadhurst PA. Cardiac sarcoid or arrhythmogenic right ventricular cardiomyopathy: a role for positron emission tomography (PET)? J Nucl Cardiol. 2013; 20(3):479-480. [PubMed: 23413193] 
157. Litovsky SH, Burke AP, Virmani R. Giant cell myocarditis: an entity distinct from sarcoidosis characterized by multiphasic myocyte destruction by cytotoxic T cells and histiocytic giant cells. Mod Pathol. 1996; 9(12):1126-1134. [PubMed: 8972471]

158. Okura Y, Dec GW, Hare JM, et al. A clinical and histopathologic comparison of cardiac sarcoidosis and idiopathic giant cell myocarditis. J Am Coll Cardiol. 2003; 41(2):322-329. [PubMed: 12535829]

159. Yoshizawa S, Kato TS, Mancini D, Marboe CC. Outcome of patients having heart transplantation for lymphocytic myocarditis. Am J Cardiol. 2013; 112(3):405-410. [PubMed: 23623331]

160. Mavrogeni S, Sfikakis PP, Gialafos E, et al. Cardiac tissue characterization and the diagnostic value of cardiovascular magnetic resonance in systemic connective tissue diseases. Arthritis Care Res (Hoboken). 2014; 66(1):104-112. [PubMed: 24106233]

161. Kang EJ, Kim SM, Choe YH, Lee GY, Lee KN, Kim DK. Takayasu arteritis: assessment of coronary arterial abnormalities with 128-section dual-source CT angiography of the coronary arteries and aorta. Radiology. 2014; 270(1):74-81. [PubMed: 24009351]

162. Miszalski-Jamka T, Szczeklik W, Sokołowska B, et al. Standard and feature tracking magnetic resonance evidence of myocardial involvement in Churg-Strauss syndrome and granulomatosis with polyangiitis (Wegener's) in patients with normal electro-cardiograms and transthoracic echocardiography. Int J Cardiovasc Imaging. 2013; 29(4):843-853. [PubMed: 23212274]

163. Mohty D, Damy T, Cosnay P, et al. Cardiac amyloidosis: updates in diagnosis and management. Arch Cardiovasc Dis. 2013; 106(10):528-540. [PubMed: 24070600]

164. Marques N, Gan VC, Leo YS. Dengue myocarditis in Singapore: two case reports. Infection. 2013; 41(3):709-714. [PubMed: 23277366]

165. Nunes MC, Dones W, Morillo CA, Encina JJ, Ribeiro AL, Council on Chagas Disease of the Inter-American Society of Cardiology. Chagas disease: an overview of clinical and epidemiological aspects. J Am Coll Cardiol. 2013; 62(9):767-776. [PubMed: 23770163]

166. Homsi M, Alsayed L, Safadi B, Mahenthiran J, Das MK. Fragmented QRS complexes on 12-lead ECG: a marker of cardiac sarcoidosis as detected by gadolinium cardiac magnetic resonance imaging. Ann Noninvasive Electrocardiol. 2009; 14(4):319-326. [PubMed: 19804507]

167. Takagi M, Yokoyama Y, Aonuma K, Aihara N, Hiraoka M, Japan Idiopathic Ventricular Fibrillation Study (J-IVFS) Investigators. Clinical characteristics and risk stratification in symptomatic and asymptomatic patients with brugada syndrome: multicenter study in Japan. J Cardiovasc Electrophysiol. 2007; 18(12):1244-1251. [PubMed: 17900255]

168. Priori SG, Gasparini M, Napolitano C, et al. Risk stratification in Brugada syndrome: results of the PRELUDE (PRogrammed ELectrical stimUlation preDictive valuE) registry. J Am Coll Cardiol. 2012; 59(1):37-45. [PubMed: 22192666]

169. Catalano O, Antonaci S, Moro G, et al. Magnetic resonance investigations in Brugada syndrome reveal unexpectedly high rate of structural abnormalities. Eur Heart J. 2009; 30(18):2241-2248. [PubMed: 19561025]

170. Quarta G, Husain SI, Flett AS, et al. Arrhythmogenic right ventricular cardiomyopathy mimics: role of cardiovascular magnetic resonance. J Cardiovasc Magn Reson. 2013; 15:16. [PubMed: 23398958]

171. Steckman DA, Schneider PM, Schuller JL, et al. Utility of cardiac magnetic resonance imaging to differentiate cardiac sarcoidosis from arrhythmogenic right ventricular cardiomyopathy. Am J Cardiol. 2012; 110(4):575-579. [PubMed: 22595349]

172. Mehta D, Lubitz SA, Frankel Z, et al. Cardiac involvement in patients with sarcoidosis: diagnostic and prognostic value of outpatient testing. Chest. 2008; 133(6):1426-1435. [PubMed: 18339784]

173. Mehta D, Mori N, Goldbarg SH, Lubitz S, Wisnivesky JP, Teirstein A. Primary prevention of sudden cardiac death in silent cardiac sarcoidosis: role of programmed ventricular stimulation. Circ Arrhythm Electrophysiol. 2011; 4(1):43-48. [PubMed: 21193539]

174. Uusimaa P, Ylitalo K, Anttonen O, et al. Ventricular tachyarrhythmia as a primary presentation of sarcoidosis. Europace. 2008; 10(6):760-766. [PubMed: 18456644] 
175. Kato Y, Morimoto S, Uemura A, Hiramitsu S, Ito T, Hishida H. Efficacy of corticosteroids in sarcoidosis presenting with atrioventricular block. Sarcoidosis Vasc Diffuse Lung Dis. 2003; 20(2):133-137. [PubMed: 12870723]

176. Pierre-Louis B, Prasad A, Frishman WH. Cardiac manifestations of sarcoidosis and therapeutic options. Cardiol Rev. 2009; 17(4):153-158. [PubMed: 19525676]

177. Sadek MM, Yung D, Birnie DH, Beanlands RS, Nery PB. Corticosteroid therapy for cardiac sarcoidosis: a systematic review. Can J Cardiol. 2013; 29(9):1034-1041. [PubMed: 23623644]

178. Grutters JC, van den Bosch JM. Corticosteroid treatment in sarcoidosis. Eur Respir J. 2006; 28(3):627-636. [PubMed: 16946094]

179. Baughman RP, Culver DA, Judson MA. A concise review of pulmonary sarcoidosis. Am J Respir Crit Care Med. 2011; 183(5):573-581. [PubMed: 21037016]

180. Sugisaki K, Yamaguchi T, Nagai S, et al. Clinical characteristics of 195 Japanese sarcoidosis patients treated with oral corticosteroids. Sarcoidosis Vasc Diffuse Lung Dis. 2003; 20(3):222226. [PubMed: 14620165]

181. Yodogawa K, Seino Y, Ohara T, Takayama H, Katoh T, Mizuno K. Effect of corticosteroid therapy on ventricular arrhythmias in patients with cardiac sarcoidosis. Ann Noninvasive Electrocardiol. 2011; 16(2):140-147. [PubMed: 21496164]

182. Yodogawa K, Seino Y, Shiomura R, et al. Recovery of atrioventricular block following steroid therapy in patients with cardiac sarcoidosis. J Cardiol. 2013; 62(5):320-325. [PubMed: 24016620]

183. Stees CS, Khoo MS, Lowery CM, Sauer WH. Ventricular tachycardia storm successfully treated with immunosuppression and catheter ablation in a patient with cardiac sarcoidosis. J Cardiovasc Electrophysiol. 2011; 22(2):210-213. [PubMed: 20561106]

184. Hiramastu S, Tada H, Naito S, Oshima S, Taniguchi K. Steroid treatment deteriorated ventricular tachycardia in a patient with right ventricle-dominant cardiac sarcoidosis. Int J Cardiol. 2009; 132(2):e85-e87. [PubMed: 18037174]

185. Lazar CA, Culver DA. Treatment of sarcoidosis. Semin Respir Crit Care Med. 2010; 31(4):501518. [PubMed: 20665400]

186. Wang T, Weigt SS, Belperio JA, Lynch JP III. Immunosuppressive and cytotoxic therapy: pharmacology, toxicities, and monitoring. Semin Respir Crit Care Med. 2011; 32(3):346-370. [PubMed: 21674420]

187. Lynch JP III, McCune WJ. Immunosuppressive and cytotoxic pharmacotherapy for pulmonary disorders. Am J Respir Crit Care Med. 1997; 155(2):395-420. [PubMed: 9032171]

188. Demeter SL. Myocardial sarcoidosis unresponsive to steroids. Treatment with cyclophosphamide. Chest. 1988; 94(1):202-203. [PubMed: 3383636]

189. Barnabe C, McMeekin J, Howarth A, Martin L. Successful treatment of cardiac sarcoidosis with infliximab. J Rheumatol. 2008; 35(8):1686-1687. [PubMed: 18671332]

190. Uthman I, Touma Z, Khoury M. Cardiac sarcoidosis responding to monotherapy with infliximab. Clin Rheumatol. 2007; 26(11):2001-2003. [PubMed: 17394036]

191. Mezaki T, Chinushi M, Washizuka T, et al. Discrepancy between inducibility of ventricular tachycardia and activity of cardiac sarcoidosis. Requirement of defibrillator implantation for the inactive stage of cardiac sarcoidosis. Intern Med. 2001; 40(8):731-735. [PubMed: 11518112]

192. Huang PL, Brooks R, Carpenter C, Garan H. Antiarrhythmic therapy guided by programmed electrical stimulation in cardiac sarcoidosis with ventricular tachycardia. Am Heart J. 1991; 121(2):599-601. Pt 1. [PubMed: 1990769]

193. Kowey PR, Waxman HL, Greenspon A, et al. Philadelphia Arrhythmia Group. Value of electrophysiologic testing in patients with previous myocardial infarction and nonsustained ventricular tachycardia. Am J Cardiol. 1990; 65(9):594-598. [PubMed: 2309629]

194. Poll DS, Marchlinski FE, Buxton AE, Josephson ME. Usefulness of programmed stimulation in idiopathic dilated cardiomyopathy. Am J Cardiol. 1986; 58(10):992-997. [PubMed: 3776856]

195. Shabetai R. Sarcoidosis and the heart. Curr Treat Options Cardiovasc Med. 2000; 2(5):385-398. [PubMed: 11096543]

196. Stein E, Jackler I, Stimmel B, Stein W, Siltzbach LE. Asymptomatic electrocardiographic alterations in sarcoidosis. Am Heart J. 1973; 86(4):474-477. [PubMed: 4728123] 
197. Takada K, Ina Y, Yamamoto M, Satoh T, Morishita M. Prognosis after pacemaker implantation in cardiac sarcoidosis in Japan. Clinical evaluation of corticosteroid therapy. Sarcoidosis. 1994; 11(2):113-117. [PubMed: 7809494]

198. Paz HL, McCormick DJ, Kutalek SP, Patchefsky A. The automated implantable cardiac defibrillator. Prophylaxis in cardiac sarcoidosis. Chest. 1994; 106(5):1603-1607. [PubMed: 7956431]

199. Betensky BP, Tschabrunn CM, Zado ES, et al. Long-term follow-up of patients with cardiac sarcoidosis and implantable cardioverter-defibrillators. Heart Rhythm. 2012; 9(6):884-891. [PubMed: 22338670]

200. Chinushi M, Mezaki T, Aoki Y, Nakagawa I, Washizuka T, Aizawa Y. Demonstration of transient entrainment in monomorphic sustained ventricular tachycardia associated with cardiac sarcoidosis. Jpn Circ J. 2000; 64(8):635-637. [PubMed: 10952165]

201. Epstein AE, DiMarco JP, Ellenbogen KA, et al. American College of Cardiology/American Heart Association Task Force on Practice Guidelines (Writing Committee to Revise the ACC/AHA/ NASPE 2002 Guideline Update for Implantation of Cardiac Pacemakers and Antiarrhythmia Devices); American Association for Thoracic Surgery; Society of Thoracic Surgeons. ACC/AHA/HRS 2008 Guidelines for Device-Based Therapy of Cardiac Rhythm Abnormalities: a report of the American College of Cardiology/American Heart Association Task Force on Practice Guidelines (Writing Committee to Revise the ACC/AHA/NASPE 2002 Guideline Update for Implantation of Cardiac Pacemakers and Antiarrhythmia Devices) developed in collaboration with the American Association for Thoracic Surgery and Society of Thoracic Surgeons. J Am Coll Cardiol. 2008; 51(21):e1-e62. [PubMed: 18498951]

202. Kron J, Sauer W, Schuller J, et al. Efficacy and safety of implantable cardiac defibrillators for treatment of ventricular arrhythmias in patients with cardiac sarcoidosis. Europace. 2013; 15(3): 347-354. [PubMed: 23002195]

203. Koplan BA, Soejima K, Baughman K, Epstein LM, Stevenson WG. Refractory ventricular tachycardia secondary to cardiac sarcoid: electrophysiologic characteristics, mapping, and ablation. Heart Rhythm. 2006; 3(8):924-929. [PubMed: 16876741]

204. Jefic D, Joel B, Good E, et al. Role of radiofrequency catheter ablation of ventricular tachycardia in cardiac sarcoidosis: report from a multicenter registry. Heart Rhythm. 2009; 6(2):189-195. [PubMed: 19187909]

205. Harris IM, Guarino R. Cardiac sarcoidosis: a new approach to treatment. Cardiovasc Surg. 1994; 2(3):420-422. [PubMed: 8049989]

206. Chang TI, Chi NH, Chou NK, et al. Isolated cardiac sarcoidosis in heart transplantation. Transplant Proc. 2012; 44(4):903-906. [PubMed: 22564580]

207. Perkel D, Czer LS, Morrissey RP, et al. Heart transplantation for end-stage heart failure due to cardiac sarcoidosis. Transplant Proc. 2013; 45(6):2384-2386. [PubMed: 23953552]

208. Milman N, Andersen CB, Mortensen SA, Sander K. Cardiac sarcoidosis and heart transplantation: a report of four consecutive patients. Sarcoidosis Vasc Diffuse Lung Dis. 2008; 25(1):51-59. [PubMed: 19070261]

209. Akashi H, Kato TS, Takayama H, et al. Outcome of patients with cardiac sarcoidosis undergoing cardiac transplantation—single-center retrospective analysis. J Cardiol. 2012; 60(5):407-410. [PubMed: 22890069]

210. Donsky AS, Escobar J, Capehart J, Roberts WC. Heart transplantation for undiagnosed cardiac sarcoidosis. Am J Cardiol. 2002; 89(12):1447-1450. [PubMed: 12062749]

211. Zaidi AR, Zaidi A, Vaitkus PT. Outcome of heart transplantation in patients with sarcoid cardiomyopathy. J Heart Lung Transplant. 2007; 26(7):714-717. [PubMed: 17613402]

212. Oni AA, Hershberger RE, Norman DJ, et al. Recurrence of sarcoidosis in a cardiac allograft: control with augmented corticosteroids. J Heart Lung Transplant. 1992; 11(2):367-369. Pt 1. [PubMed: 1576143]

213. Khan R, Tweedie EJ, Pflugfelder PW, White JA. Cardiac sarcoid in a heart transplant recipient: detection with cardiac magnetic resonance imaging. Transplant Proc. 2010; 42(5):1976-1978. [PubMed: 20620560] 
214. Luk A, Lee A, Ahn E, Soor GS, Ross HJ, Butany J. Cardiac sarcoidosis: recurrent disease in a heart transplant patient following pulmonary tuberculosis infection. Can J Cardiol. 2010; 26(7):e273-e275. [PubMed: 20847976]

215. Yager JE, Hernandez AF, Steenbergen C, et al. Recurrence of cardiac sarcoidosis in a heart transplant recipient. J Heart Lung Transplant. 2005; 24(11):1988-1990. [PubMed: 16297811]

216. Langah R, Spicer K, Gebregziabher M, Gordon L. Effectiveness of prolonged fasting 18f-FDG PET-CT in the detection of cardiac sarcoidosis. J Nucl Cardiol. 2009; 16(5):801-810. [PubMed: 19548047] 

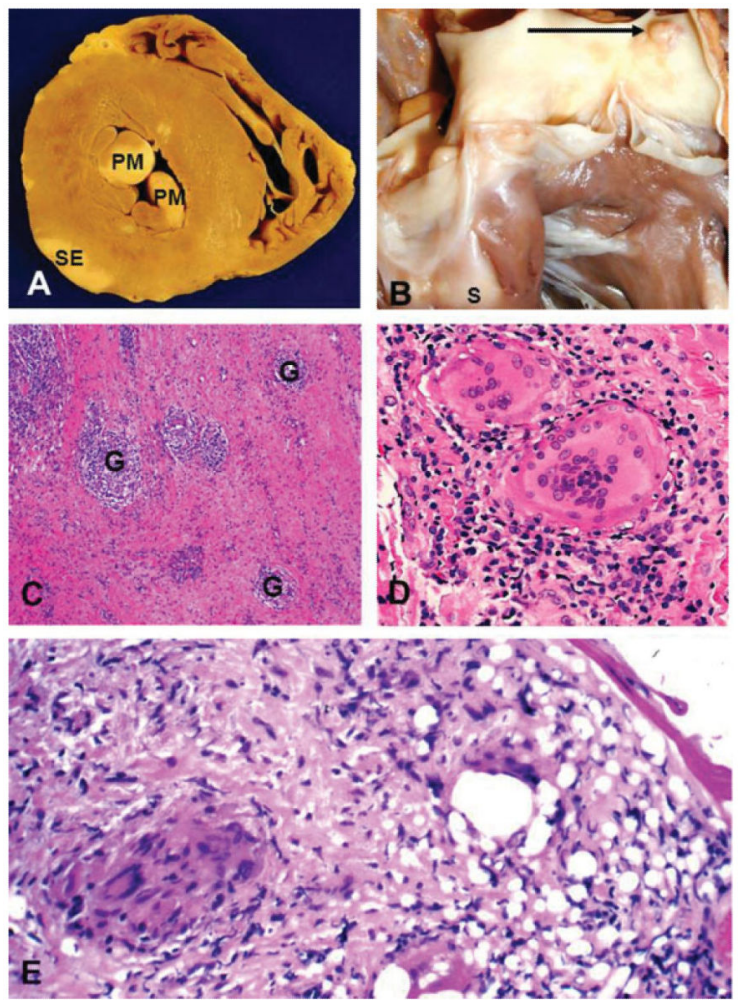

Fig. 1.

(A-E) Photomicrographs. (A and B): Gross photographs of heart from young man dying suddenly while playing basketball. (A) Cross-section of ventricles showing scars in papillary muscles (PM) and subepicardium (SE) with normal coronary artery characteristic of sarcoid lesions as opposed to ischemic injury. (B) Right ventricular outflow tract from same patient showing scarring below the pulmonary valve $(\mathrm{S})$ and a granuloma in the pulmonary artery (arrow). (C) Histologic section of left ventricular lesion showing typical discrete, wellcircumscribed nonnecrotizing granulomas $(\mathrm{G})$ typical of sarcoidosis (hematoxylin and eosin $[\mathrm{H} \& \mathrm{E}]$ stain, $\times 40)$. (D) High magnification showing typical giant cells with numerous nuclei (H\&E stain, $\times 400)$. (E) Endomyocardial biopsy from patient resuscitated from sudden cardiac death, showing nonnecrotizing granuloma (NNG) typical of sarcoidosis (H\&E stain, $\times 200)$. 


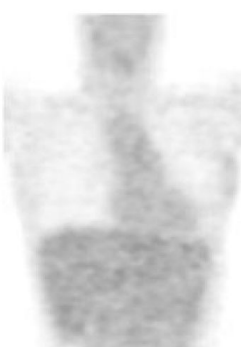

Transaxial view

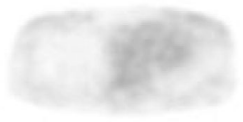

'None' pattern
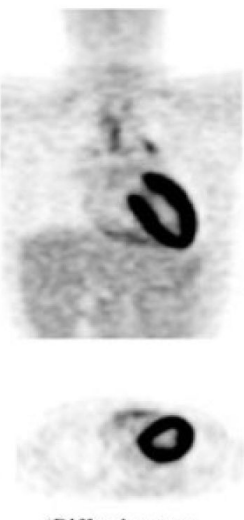

'Diffuse' pattern
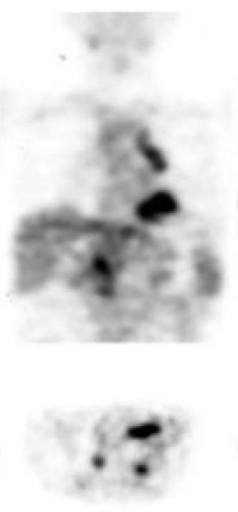

'Focal' pattern
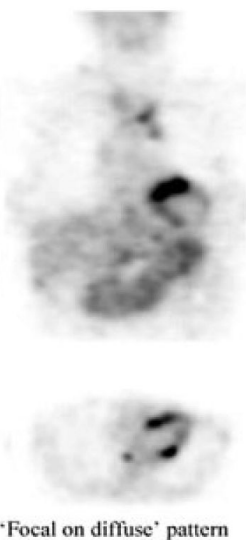

Fig. 2.

Patterns of myocardial ${ }^{18} \mathrm{FDG}$ uptake on PET scan (reproduced with permission from Ishimaru et al ${ }^{121}$ ). ${ }^{18} \mathrm{FDG}, 18 \mathrm{~F}$-fluorodeoxyglucose; PET, positron emission tomography. 


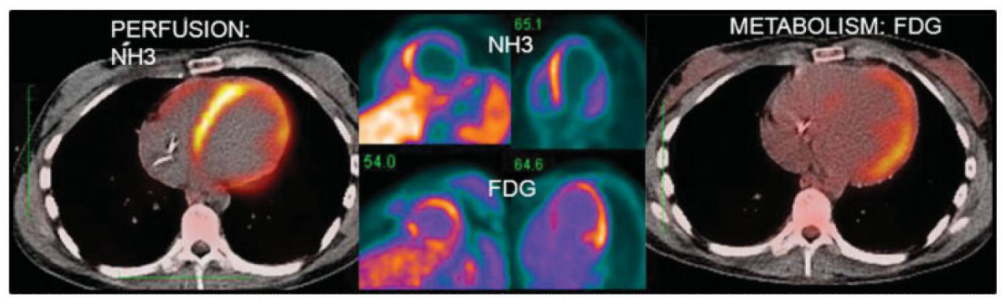

Fig. 3.

Patient with nonischemic cardiomyopathy and VT with mismatch. Perfusion shows normal septal uptake with decreased lateral uptake by NH3. On ${ }^{18}$ FDG-PET, the myocardial uptake is increased on the lateral wall, which indicates inflammation. ${ }^{18} \mathrm{FDG}, 18 \mathrm{~F}-$

fluorodeoxyglucose; PET, positron emission tomography; VT, ventricular tachycardia. 


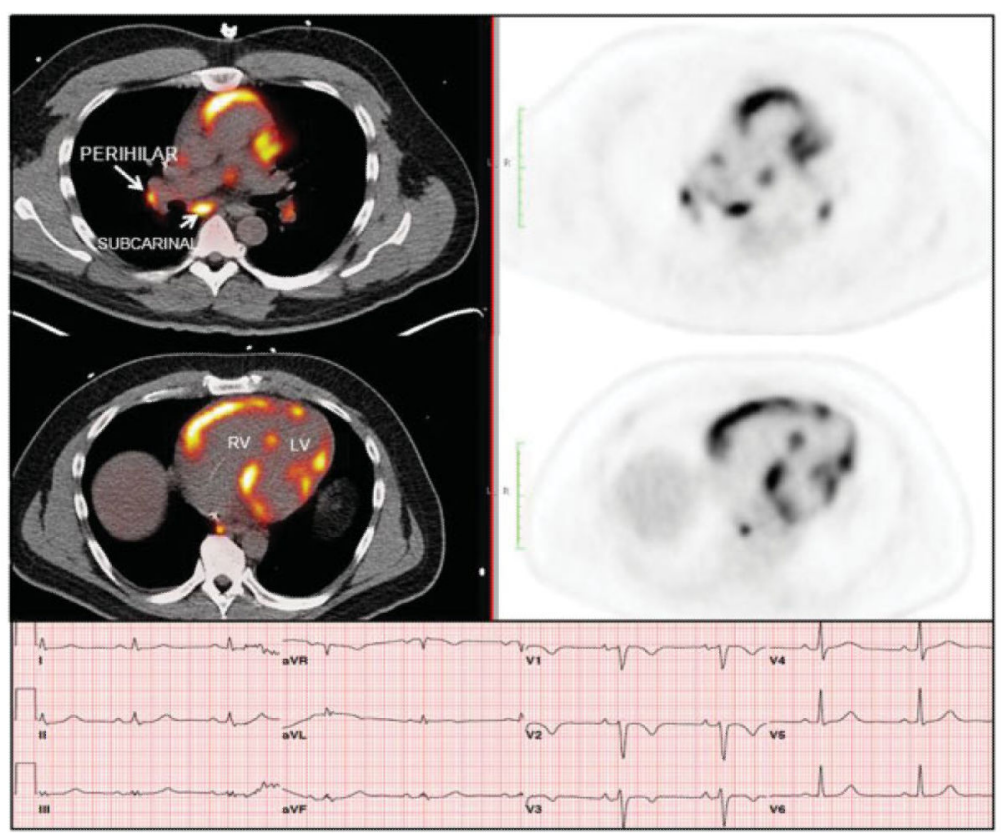

Fig. 4.

Patient with VT referred for ablation with presumed arrhythmogenic right ventricular dysplasia with right precordial T wave inversion. PET/ CT demonstrated extracardiac ${ }^{18}$ FDG uptake in right hilar lymph node and patchy focal uptake throughout both ventricles. Biopsy of the right hilar node confirmed NNG consistent with sarcoidosis. ${ }^{18}$ FDG, 18F-fluorodeoxyglucose; NNG, nonnecrotizing granuloma; PET, positron emission tomography; VT, ventricular tachycardia. 


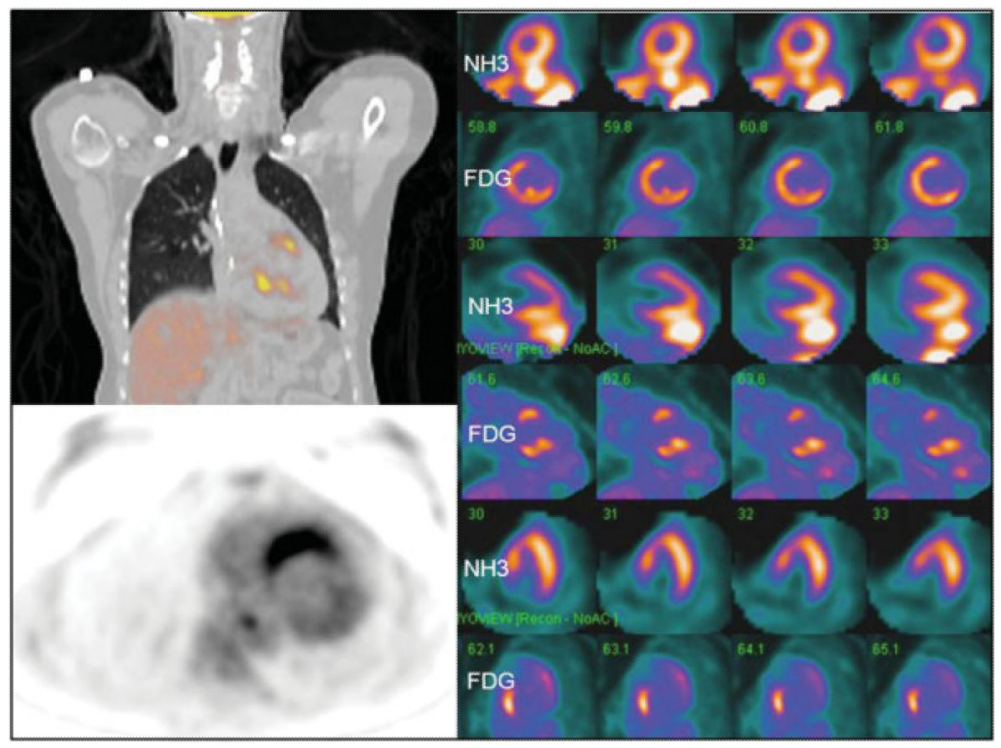

Fig. 5.

Multiphase inflammation in a 49-year-old female with a history of heart block requiring a pacemaker. Nonsustained VT was documented on pacer interrogation. PET/CT revealed decreased anteroseptal perfusion with focal uptake of ${ }^{18} \mathrm{FDG}$ in the septum and inferolateral wall. The mismatch in the septum suggests chronic scarring. ${ }^{18} \mathrm{FDG}, 18 \mathrm{~F}-$

fluorodeoxyglucose; NNG, nonnecrotizing granuloma; PET, positron emission tomography; VT, ventricular tachycardia. 


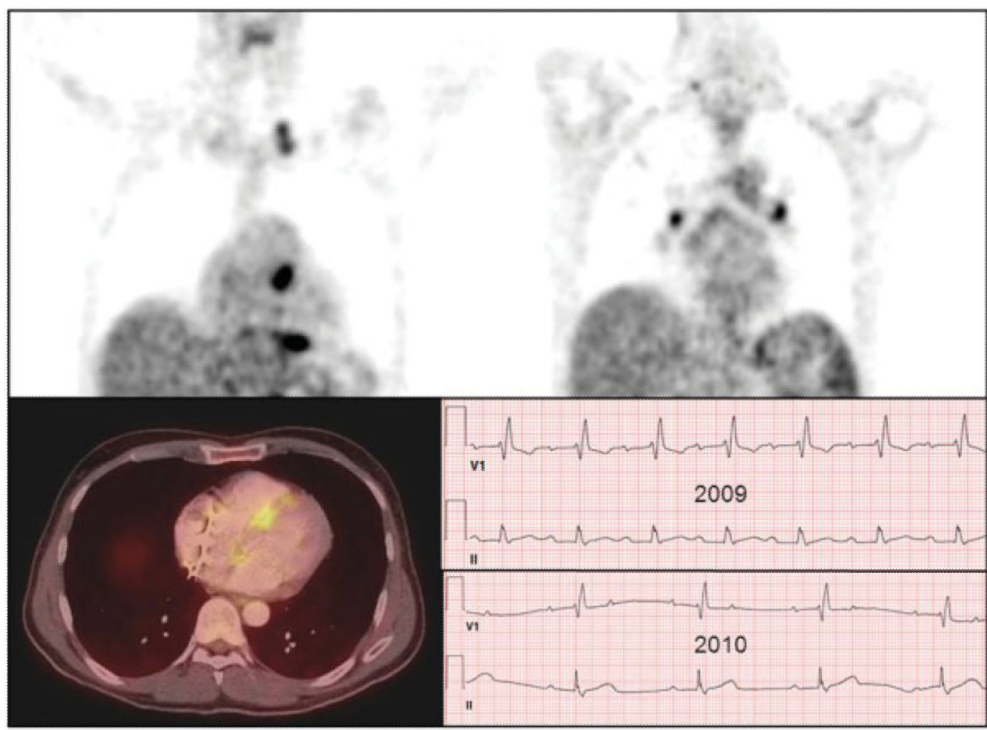

Fig. 6.

Typical bilateral hilar update and patchy myocardial uptake in the septum with progressive heart block in a patient presenting with intermittent lightheadedness. 


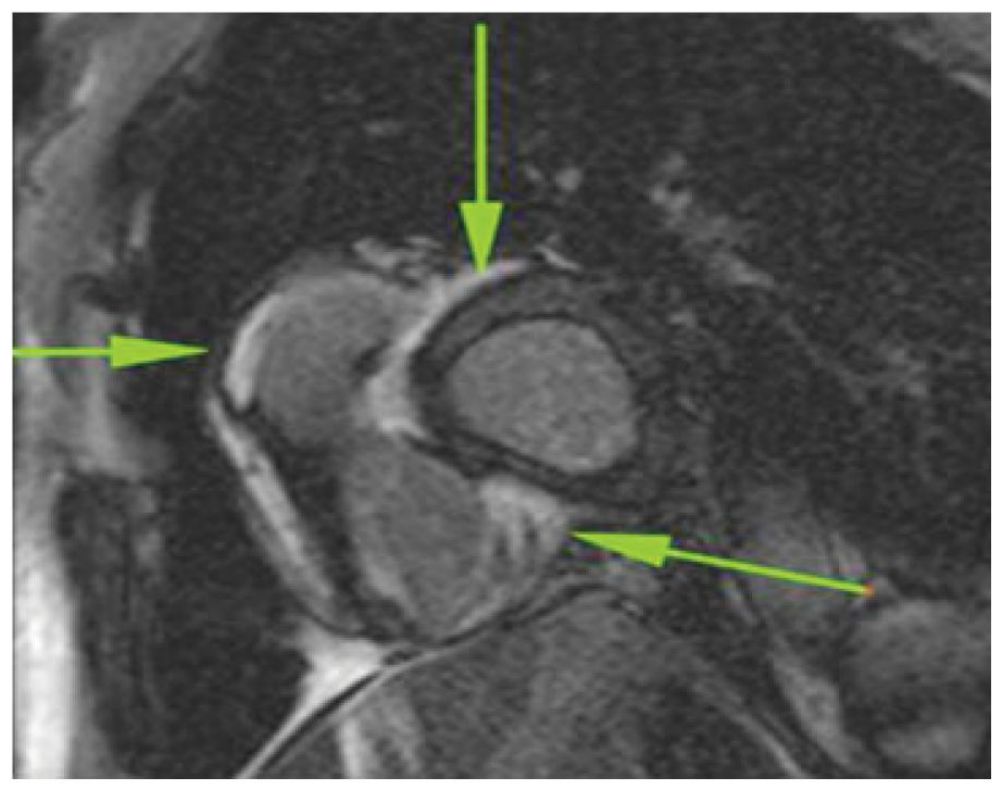

Fig. 7.

MRI scan showing delayed enhancement throughout RV in a 48-year-old male with recurrent VT of RV origin and suspected ARVC. An ICD was placed and he subsequently had recurrent ICD shocks. He was referred for VT ablation. MRI showed diffuse hyperenhancement of the RV extending into the IVS. The RV was dilated and hypokinetic. PET/CT showed intense ${ }^{18} \mathrm{FDG}$ uptake in the interior wall and most of the RV free wall, with diffuse lymph node uptake (arrows). Lymph node biopsy revealed NNG consistent with sarcoidosis. With treatment of his sarcoidosis, VT has not recurred. CT, computed tomography; ${ }^{18} \mathrm{FDG}, 18 \mathrm{~F}$-fluorodeoxyglucose; ICD, implantable cardioverter-defibrillators; MRI, magnetic resonance imaging; NNG, nonnecrotizing granuloma; PET, positron emission tomography; RV, right ventricle; VT, ventricular tachycardia 


\section{Table 1}

Japanese ministry of health and welfare guidelines for diagnosis of cardiac sarcoidosis, 2006 version (adapted and revised from Hiraga et al, 1993) 73

\begin{tabular}{|c|c|}
\hline \multicolumn{2}{|c|}{ Histologic diagnosis group } \\
\hline \multicolumn{2}{|c|}{$\begin{array}{l}\text { Confirmed when myocardial biopsy demonstrates noncaseating epithelioid cell granuloma with histological } \\
\text { or clinical diagnosis of extracardiac sarcoidosis }\end{array}$} \\
\hline \multicolumn{2}{|c|}{ Clinical diagnosis group } \\
\hline \multicolumn{2}{|c|}{ Negative myocardial biopsy but extracardiac sarcoidosis is diagnosed histologically or clinically and } \\
\hline \multicolumn{2}{|c|}{$2+$ of 4 major criteria are satisfied or } \\
\hline \multicolumn{2}{|c|}{$1+$ of 4 major and $2+$ of 5 minor } \\
\hline \multirow[t]{4}{*}{ Major criteria } & Advanced AV block \\
\hline & Basal thinning of the interventricular septum \\
\hline & Positive cardiac ${ }^{67} \mathrm{Ga}$ uptake \\
\hline & Depressed LVEF $<50 \%$ \\
\hline \multirow[t]{5}{*}{ Minor criteria } & $\begin{array}{l}\text { Abnormal ECG findings: ventricular arrhythmias (VT, multifocal or frequent PVCs, } \\
\text { right BBB, axis deviation, or abnormal Q-wave }\end{array}$ \\
\hline & $\begin{array}{l}\text { Abnormal echocardiography: regional abnormal wall motion or morphological abnormality } \\
\text { (ventricular aneurysm, wall thickening) }\end{array}$ \\
\hline & $\begin{array}{l}\text { Nuclear medicine: perfusion defect detected by } 201 \mathrm{TI} \text { myocardial scintigraphy } \\
\text { or }{ }^{99} \mathrm{Tc} \text { myocardial scintigraphy }\end{array}$ \\
\hline & Gadolinium-enhanced MRI: delayed enhancement of myocardium \\
\hline & Endomyocardial biopsy: interstitial fibrosis or monocyte infiltrate over moderate grade \\
\hline
\end{tabular}

Abbreviations: AV, atrioventricular; BBB, bundle branch block; ECG, electrocardiogram; MRI, magnetic resonance imaging; LVEF, left ventricular ejection fraction; PVCs, premature ventricular contractions 
Table 2

Sensitivity of PET for cardiac sarcoid

\begin{tabular}{|c|c|c|c|c|c|c|}
\hline Study & Year & $\begin{array}{l}\text { Number } \\
\text { of patients }\end{array}$ & Cohort & $\begin{array}{l}\text { Diagnosis of } \\
\text { cardiac sarcoid }\end{array}$ & $\begin{array}{l}\text { Sensitivity (\%) } \\
\text { (95\% CI) }\end{array}$ & $\begin{array}{l}\text { Specificity (\%) } \\
(95 \% \text { CI) }\end{array}$ \\
\hline Yamagishi et al ${ }^{123}$ & 2003 & 17 & Cardiac sarcoid & Histologic & $\begin{array}{l}82 \\
(0.57-0.96)\end{array}$ & $\mathrm{n} / \mathrm{a}$ \\
\hline Okumura et al ${ }^{118}$ & 2004 & 22 & Sarcoid & Histologic & $\begin{array}{l}100 \\
(0.72-1.00)\end{array}$ & $\begin{array}{l}91 \\
(0.59-1.00)\end{array}$ \\
\hline Ishimaru et al ${ }^{121}$ & 2005 & 32 & Sarcoid & Clinical & $\begin{array}{l}100 \\
(0.48-1.00)\end{array}$ & $\begin{array}{l}81 \\
(0.62-0.94)\end{array}$ \\
\hline Nishiyama et al ${ }^{111}$ & 2006 & 18 & Sarcoid & Clinical & $\begin{array}{l}100 \\
(0.59-1.00)\end{array}$ & $\begin{array}{l}100 \\
(0.72-1.00)\end{array}$ \\
\hline Ohira et al ${ }^{125}$ & 2008 & 21 & $\begin{array}{l}\text { Suspected } \\
\text { cardiac sarcoid }\end{array}$ & Clinical & $\begin{array}{l}88 \\
(0.47-1.00)\end{array}$ & $\begin{array}{l}38 \\
(0.14-0.68)\end{array}$ \\
\hline Langah et al ${ }^{216}$ & 2009 & 30 & $\begin{array}{l}\text { Suspected } \\
\text { cardiac sarcoid }\end{array}$ & Clinical & $\begin{array}{l}85 \\
(0.62-0.97)\end{array}$ & $\begin{array}{l}90 \\
(0.55-1.00)\end{array}$ \\
\hline Ontario CADRE ${ }^{79}$ & $2007-2010$ & 24 & $\begin{array}{l}\text { Suspected } \\
\text { cardiac sarcoid }\end{array}$ & & $\begin{array}{l}89 \\
(0.79-0.96)\end{array}$ & $\begin{array}{l}78 \\
(0.68-0.86)\end{array}$ \\
\hline Weighted mean & & 164 & & & $\begin{array}{l}89.9 \\
(0.79-0.96)\end{array}$ & $\begin{array}{l}78 \\
(0.68-0.86)\end{array}$ \\
\hline
\end{tabular}

Abbreviations: CI, confidence interval; PET, positron emission tomography. 


\section{Table 3}

Treatment of cardiac sarcoidosis (reproduced from Deng et al, 2002 ${ }^{21}$ )

\begin{tabular}{|l|l|}
\hline Treatment modality & Indication \\
\hline CS & $\begin{array}{l}\text { Conventional therapy (for initial treatment, long-term maintenance, } \\
\text { and relapses) }\end{array}$ \\
\hline Hydroxychloroquine $(200 \mathrm{mg}$ bid) & Steroid sparing; adjunct to CS \\
\hline Azathioprine (100-200 mg/d) & Steroid sparing; adjunct to CS \\
\hline Methotrexate (10-20 mg once weekly) & Steroid sparing; adjunct to CS \\
\hline Cyclophosphamide $(1-2 \mathrm{mg} / \mathrm{kg} / \mathrm{d})$ & Refractory to other medical therapy \\
\hline Antiarrhythmic agents & Serious tachyarrhythmias \\
\hline Automatic implantable cardioverter-defibrillator & For documented arrhythmias, heart block, or syncope \\
\hline Surgical resection of ventricular aneurysms & Serious tachyarrhythmias \\
\hline Heart transplantation & Severe cardiac failure, refractory to medical therapy \\
\hline
\end{tabular}

Abbreviation: CS, corticosteroids. 